\title{
Desenvolvimento de barra de cereais com aproveitamento de resíduo de mosturação de cerveja desidratado e incorporação de proteína hidrolisada de soja e gelatina
}

\author{
Development of cereal bar using dehydrated brassage pomace and incorporation of hydrolyzed soy
}

protein and gelatin

Elaboración de barrita de cereales a partir de orujo de maceración deshidratado e incorporación de proteína de soja hidrolizada y gelatina

\section{Resumo}

O resíduo de mosturação é o subproduto gerado em maior quantidade durante o processamento da cerveja. Este resíduo possui teor elevado de proteínas, minerais, fibras alimentares e água. Os processos de secagem permitem o aumento da vida de prateleira do resíduo da mosturação e a aplicação em produtos alimentícios. Dentre estes produtos, as barras de cereais possuem excelente potencial, por estarem em ampla expansão no mercado e serem uma matriz alimentícia de fácil manuseio. Além do aumento nos teores de fibras alimentares, a incorporação de proteínas melhora o perfil nutricional das barras de cereais. Desta forma, objetivamos realizar o processo de secagem do resíduo de mosturação a três temperaturas $\left(40,60\right.$ e $\left.80^{\circ} \mathrm{C}\right)$ e aplicá-lo em barras de cereais adicionadas de proteína hidrolisada de soja e gelatina. A Metodologia de Superfície de Resposta foi utilizada como estratégia experimental, através de um Delineamento Composto Central Rotacional de três variáveis independentes. As respostas avaliadas foram a cor e textura instrumental, densidade aparente, atividade de água e umidade. $\mathrm{O}$ ponto otimizado $\left(\mathrm{p}<0,10\right.$ e $\left.\mathrm{R}^{2}>0,80\right)$ foi definido com o uso de $27,08 \%$ de resíduo de mosturação, $12,44 \%$ de proteína hidrolisada de soja e 0,89 \% de gelatina hidratada (1:3 - razão gelatina:água). Observou-se que o ponto otimizado apresentou características tecnológicas satisfatórias, com redução significativa nos teores de lipídeos, açúcares e amido e aumento nos teores de proteínas, minerais e fibras alimentares. O ponto otimizado apresentou uma redução de 19,27 \% no valor calórico total.

Palavras-chave: Agentes ligantes; Aminoácidos; Fibras alimentares; Secagem; Textura.

\begin{abstract}
The brassage pomace is the by-product generated in greater amounts during beer processing. This residue has a high content of proteins, minerals, dietary fiber, and water content. Drying processes allow for an increase in the shelf life of the brassage pomace and its application in food products. Among these products, cereal bars have excellent potential, as they are expanding widely in the market and are an easy-to-handle food matrix. In addition to the increase in dietary fiber content, the incorporation of proteins improves the nutritional profile of cereal bars. Thus, we aim to carry out the drying process of the brassage pomace at three temperatures $\left(40,60\right.$ and $\left.80{ }^{\circ} \mathrm{C}\right)$ and apply it to cereal bars with hydrolyzed soy protein and gelatin. The Response Surface Methodology was used as an experimental strategy through a Central Composite Rotational Design of three independent variables. The evaluated responses were instrumental color and texture, bulk density, water activity and moisture. The optimal point $\left(P<0.10\right.$ and $\left.\mathrm{R}^{2}>0.80\right)$ was defined using $27.08 \%$ brassage pomace, $12.44 \%$ hydrolyzed soy protein and $0.89 \%$ hydrated gelatin $(1: 3-$ gelatin:water ratio). It was observed that the optimized point presented satisfactory technological characteristics, with
\end{abstract}


a significant reduction in the levels of lipids, sugars and starch and an increase in the levels of proteins, minerals and dietary fiber. In addition, the optimized point showed a $19.27 \%$ reduction in the total caloric value.

Keywords: Amino acids; Binding agents; Dietary fiber; Drying; Texture.

\begin{abstract}
Resumen
El residuo de la maceración es el subproducto generado en mayor cantidad durante el procesamiento de la cerveza. Este residuo tiene un alto contenido de proteínas, minerales, fibra dietética y agua. Los procesos de secado permiten aumentar la vida útil de los residuos de maceración y su aplicación en productos alimenticios. Entre estos productos, las barras de cereales tienen un excelente potencial, ya que se están expandiendo ampliamente en el mercado y son una matriz alimentaria de fácil manejo. Además del aumento del contenido de fibra dietética, la incorporación de proteínas mejora el perfil nutricional de las barritas de cereales. Así, se pretende realizar el proceso de secado del residuo de maceración en tres temperaturas $\left(40,60\right.$ y $\left.80^{\circ} \mathrm{C}\right)$ y aplicarlo en barras de cereales adicionadas con proteína de soja hidrolizada y gelatina. Se utilizó la Metodología de Superficie de Respuesta como estrategia experimental por medio de un Diseño Rotacional Compuesto Central con tres variables independientes. Las respuestas evaluadas fueron color y textura instrumental, densidad aparente, actividad de agua y humedad. El punto optimizado ( $\mathrm{p}<0,10$ y $\left.\mathrm{R}^{2}>0,80\right)$ se definió utilizando $27,08 \%$ de residuo de maceración, $12,44 \%$ de proteína de soya hidrolizada y $0,89 \%$ de gelatina hidratada (1:3 - relación gelatina:agua). Se observó que el punto optimizado presentó características tecnológicas satisfactorias, con reducción significativa de los niveles de lípidos, azúcares y almidón y aumento de los niveles de proteínas, minerales y fibra dietética. El punto optimizado mostró una reducción del 19,27 \% en el valor calórico total.
\end{abstract}

Palabras clave: Agentes aglutinantes; Aminoácidos; Fibra dietética; Secado; Textura.

\title{
1. Introdução
}

Para alcançar um estilo de vida mais saudável é necessário ter hábitos que promovam benefícios à saúde, como a prática de exercícios físicos, hidratação adequada e uma boa alimentação. No entanto, a dieta é considerada pelos consumidores como o principal efeito relacionado ao crescimento, desenvolvimento e saúde geral dos indivíduos. Pesquisas comprovam que a partir de uma dieta rica em fibras alimentares ocorre a proteção contra a desnutrição e a prevenção de doenças crônicas não transmissíveis, como vários tipos de cânceres, obesidade, diabetes e doenças cardiovasculares, além da proteção contra alguns vírus respiratórios (Antunes et al., 2019; Miller, 2020; Prado, Castro-Alves, Ferreira, \& Fabi, 2019). Além disso, o consumo de fibras alimentares promove saciedade ao indivíduo, onde os efeitos das fibras alimentares solúveis promovem a formação de um gel no trato gastrointestinal, diminuindo a velocidade de absorção da glicose. As fibras alimentares insolúveis resultam em uma alta capacidade de hidratação, fazendo com que os movimentos peristálticos sejam diminuídos, promovendo um aumento no bolo fecal e retardando o trânsito gastrointestinal, prolongando a saciedade (Bernaud \& Rodrigues, 2013).

Os carboidratos não digeríveis podem ser utilizados na indústria de alimentos como ingredientes de alto valor agregado, promotores de melhora no perfil nutricional e de baixo custo, atributos que os tornam promissores para uso nos produtos alimentícios, principalmente em produtos de panificação, bem como em outras fontes alimentícias, como barras de cereais, cookies, massas alimentícias, extrusados expandidos e derivados cárneos (Ferreira et al., 2021; Gibelato et al., 2016; Miranda \& Schmiele, 2020; Ramos, Pereira, Andressa, Schmiele, \& Amaral, 2020; Shih, Wang, Hasenbeck, Stone, \& Zhao, 2020). Dentre esses alimentos, os alimentos de conveniência, também conhecidos como snacks, ocupam lugar de destaque e são definidos como pequenas refeições, de valor nutricional leve ou substancial, que podem estar relacionados aos atributos responsáveis pela sensorialidade, prazer e bem-estar (Martins, Alves, \& Pinheiro, 2021).

As barras de cereais apresentam um crescimento acelerado no mercado por serem alimentos de fácil transporte e acesso em função da estabilidade microbiológica e integridade física, além de não requerem nenhum preparo para serem consumidas (ready-to-eat), tornando-as práticas e convenientes (Carneiro, Queiroz, Porto, \& Queiroz, 2018). O mercado mundial apresenta uma tendência de crescimento de aproximadamente $6 \%$ por ano, sendo que os fatores que impulsionam o consumo deste tipo de produto são os apelos fisiológicos funcionais e a incorporação de fibras alimentares, proteínas, frutas, 
sementes, nozes, amêndoas e ingredientes com a presença de compostos bioativos. Além disso, há a possibilidade de incorporação de potenciais benefícios para a saúde (Lasta, Ronning, Dekker, \& Cunha, 2021; Martins et al., 2021; Timm et al., 2020).

Além disso, é possível observar que a produção de barras de cereais tem um segmento específico no mercado atual pelo aporte nutricional e fisiológico (Ramos et al., 2020). Por exemplo, barras que contém vitaminas e minerais direcionadas ao público feminino, com formulações visando uma qualidade na saúde da próstata do homem, produtos específicos para pessoas portadoras de doenças crônicas não degenerativas como a diabetes, com o poder de normalizar o nível de açúcar do sangue, e barras de cereais que são produzidas para combater a osteoporose (Barbosa \& Coelho, 2008). Outro mercado emergente são as barras de cereais com alto teor proteico (proteínas do soro do leite, caseínas, ovoalbuminas ou proteína de soja) e alta fonte de energia consumidas por atletas ou praticantes de exercícios físicos regulares em academias ou ao ar livre, tanto em níveis de exercícios leves, moderados ou intensos, como o caso do crossfit, bodybuilding ou HIIT (High Intensity Interval Training) (Jiang et al., 2021).

De acordo com a Agência Nacional de Vigilância Sanitária do Ministério da Saúde, através da Resolução Diretoria Colegiada - RDC N 263, de 22 de setembro de 2005, os produtos de cereais são os produtos obtidos a partir de partes comestíveis de cereais, podendo ser submetidos a processos de maceração, moagem, extração, tratamento térmico e ou outros processos tecnológicos considerados seguros para produção de alimentos. Sendo que as barras de cereais se enquadram nesta categoria (Brasil, 2005).

Além do apelo funcional, tecnológico, fisiológico e nutricional, o uso de matérias-primas oriundas do agronegócio ou da agroindústria está em ampla expansão, pois valorizam o desenvolvimento regional, a agricultura familiar e a sustentabilidade, destacando-se a manutenção da capacidade produtiva do agroecossistema, a redução do desperdício, o aproveitamento dos subprodutos, a valoração dos coprodutos e a conservação dos recursos naturais e da biodiversidade (Borges et al., 2020; Souza \& Schmiele, 2021).

A utilização de resíduos industriais e agroindustriais para produzir produtos alimentícios é muito importante para incorporar sustentabilidade social, ambiental e econômica no processo de fabricação de cerveja. Um destes resíduos é oriundo da produção de cerveja, o qual pode não receber um fim apropriado e acarretar problemas ambientais. A produção de cerveja envolve as seguintes etapas: moagem do malte, mosturação, fervura, fermentação e maturação, no qual a mosturação é responsável pela geração do resíduo sólido (Ashraf, Ramamurthy, \& Rene, 2021). O mosto passa por uma filtração, na qual ocorre a separação da parte líquida, que realmente serve de interesse para fabricar a cerveja, e parte sólida, a qual recebe o nome de bagaço do malte ou resíduo da mosturação (Payá et al., 2019). Segundo He et al. (2020), a cada 1 hL de mosto são gerados $20 \mathrm{~kg}$ de resíduo sólido, o que corresponde a aproximadamente $85 \%$ de todos os resíduos gerados (resíduos da mosturação, fermentação e filtração) durante a etapa de processamento de cerveja. O resíduo da mosturação é um importante subproduto, pois possui um significante valor proteico e mineral, podendo ser vastamente empregado na alimentação animal e ser utilizado como fertilizante (Nóbile, Andrade, Borgea, Cantieri, \& Kawano, 2017). Além disso, o resíduo de mosturação é rico em fibras alimentares, destacando-se as fibras prebióticas $\beta$-glucanas e arabinoxilo-oligossacarídeos, e compostos fenólicos, como por exemplo o ácido ferúlico. No entanto, este resíduo possui alto teor de umidade (70 a $75 \%$ ) (Hughes \& Grafenauer, 2021; Shih et al., 2020).

Com o intuito de favorecer a conservação do resíduo de mosturação, Schmiele, Santos, Silva, \& Silveira (2017) sugerem a aplicação da tecnologia de secagem para diminuição da umidade e atividade de água a fim de prolongar a vida útil do resíduo oriundo da mosturação. Para facilitar a aplicação do resíduo desidratado, o mesmo pode ser submetido ao processo de moagem e ser aplicado na forma de farinha. A aplicação da farinha obtida do resíduo de mosturação foi estudada por Santos et al. (2019) em pães de forma, por Carvalho, Santos, Silva, Silveira, \& Schmiele (2020) na aplicação em bolo inglês e 
por Silva, Gomes, Silva, \& Schmiele (2019) no desenvolvimento de barras de frutas, um produto similar à barra de cereais. Todos os trabalhos apresentaram resultados promissores para a aplicação do resíduo da mosturação desidratado, principalmente em relação ao aumento do teor de fibras alimentares e diminuição do valor calórico dos produtos.

Além do aumento do teor de fibras alimentares em produtos alimentícios, uma abordagem para incorporação de fontes proteicas é importante, para que ocorra uma melhora no perfil nutricional. Além do perfil de aminoácidos, as proteínas isoladas apresentam excelentes teores de minerais, o que favorece a aplicação deste ingrediente. Dentre as proteínas vegetais, destaca-se a proteína de soja por apresentar baixo custo quando comparado às demais proteínas vegetais e animais (Bessada, Barreira, \& Oliveira, 2019; Vernaza, Dia, Mejia, \& Chang, 2012). As vantagens da aplicação das proteínas de soja em alimentos são: (i) fornece um bom equilíbrio na composição de aminoácidos, uma vez que todos os aminoácidos essenciais estão contidos; (ii) contém componentes fisiologicamente benéficos que comprovadamente reduzem o colesterol e reduzem o risco de hiperlipidemia e doenças cardiovasculares; (iii) tem ampla aplicação tecnológica pelas propriedades de gelificação, capacidade de emulsificação e capacidade de retenção de água e óleo. A proteína isolada de soja é composta por uma mistura de várias proteínas, sendo classificados em quatro categorias de proteínas de acordo com os coeficientes de sedimentação em 2S, 7S, 11S e 15S que sedimentam em diferentes forças gravitacionais quando a solução é submetida a uma força centrífuga. As frações 7S ( $\beta$-conglicinina) e 11S (glicinina) representam mais de $80 \%$, e a proporção 7S/11S foi relatada como sendo cerca de 0,5 a 1,3 dependendo das variedades. A conformação terciária destas frações são as responsáveis pelas propriedades tecnológicas da proteína de soja. A glicinina nativa é conhecida por ter uma estrutura compacta estabilizada por ligações dissulfeto, apresentando propriedades surfactantes (capacidade de emulsificação e formação de espuma) menor do que a da $\beta$-conglicinina, a qual não possui ligações dissulfeto na estrutura molecular (Nishinari, Fang, Guo, \& Phillips, 2014; Schmiele, Araújo, Gurgueira, \& Chang, 2015).

A proteína de soja quando submetida a um processo de hidrólise enzimática, seja por processo germinativo ou aplicação de peptidases, possui propriedades funcionais fisiológicas interessantes na prevenção da saúde dos consumidores em função da liberação de peptídeos bioativos. Os benefícios da soja para a saúde são atribuídos à presença de compostos bioativos que podem ser divididos em compostos não proteicos, como isoflavonas e saponinas, e compostos proteicos, como inibidores de Bowman-Birk e Kunitz e lunasina. Estas frações proteicas, juntamente com os peptídeos e polipeptídeos apresentam propriedades antioxidantes, anti-inflamatórias, anticarcinogências, antimutagênicas, prebióticas, antidiabéticas e antimicrobiana e efeitos imunomoduladores (Castañeda-Pérez, Jiménez-Morales, Castellanos-Ruelas, Chel-Guerrero, \& Betancur-Ancona, 2021; Dia et al., 2012; González-Montoya, Hernández-Ledesma, Silván, Mora-Escobedo, \& MartínezVillaluenga, 2018; Vernaza \& Chang, 2020; Yang et al., 2017; Zhang, Zhang, Li, \& Liu, 2020).

A aplicação das proteínas de soja (nativa ou hidrolisada) em produtos alimentícios foi bastante explorada em pães de forma (Santos, Rodrigues, Jaekel, Chang, \& Schmiele, 2017, Schmiele, Ferrari, Clerici, \& Chang, 2017), massa alimentícia sem glúten (Schmiele, Jaekel, Ishida, Chang, \& Steel, 2013), macarrão instantâneo (Vernaza \& Chang, 2020), massa alimentícia tipo espaguete (Mastelini et al., 2018; Schmiele et al., 2019a), bolo inglês (Souza \& Schmiele, 2021; Schmiele, Silva, Costa, Rodrigues, \& Chang, 2011), massa congelada para pão sem glúten (Teotônio et al., 2021) e na aplicação de proteínas texturizadas como análogos e extensores de carne (Schmiele et al., 2019b; Yoshida et al., 2017).

Além das proteínas de leguminosas, fontes de proteínas animais têm sido amplamente empregadas na indústria de alimentos. Dentre estas estão as gelatinas, as quais são macromoléculas anfifílicas naturais importantes e podem atuar como agentes surfactantes em emulsões do tipo óleo em água por meio das propriedades tensoativas. Entretanto, as emulsões formadas possuem baixa capacidade e estabilidade em relação a outras substâncias tensoativas. Nos últimos anos, muitos estudos têm sido conduzidos com o intuito de explorar o entendimento das relações entre a estrutura da gelatina com as 
propriedades tecnológicas, a fim de explorar os possíveis métodos de modificação molecular para melhorar as habilidades de estabilização de emulsão (Zang et al. 2020).

A gelatina é reconhecida por ter a capacidade de formação de géis termorreversíveis, com fusão na temperatura do corpo humano, possuindo corte elástico reversível, agradável e com brilho único. Trata-se de um ingrediente versátil, ou até mesmo insubstituível em várias aplicações alimentícias (Quiroga, 2013). A fusão da gelatina adquire um estado chamado prógel, o qual permite diversas possibilidades para a produção de alimentos (Damodaran \& Parking, 2017).

Além do poder de geleificação e espessante, a gelatina contribui para o enriquecimento proteico de diversos alimentos como barras de cereais, iogurtes, sucos, biscoitos e produtos cárneos. Nove dos dez aminoácidos essenciais ao organismo são encontrados na composição da gelatina, destacando-se a cisteína, que age no fortalecimento de cabelos e unhas; a glicina, essencial para a elasticidade e rejuvenescimento da pele; e a hidroxiprolina, o qual é necessário para a manutenção da saúde da cartilagem nas articulações (Quiroga, 2013).

A gelatina melhora a elasticidade, a consistência e a estabilidade de produtos alimentícios. Além disso, é utilizada para a redução do teor calórico sem que haja alteração de sabores nos alimentos. Além da indústria de alimentos, esta proteína é utilizada em fármacos, na medicina e em fotografias (Rojas \& Gozzo, 2017). A gelatina é uma proteína proveniente da hidrólise parcial do colágeno, o qual é o principal constituinte de peles de animais, ossos, tendões e tecido conectivo. Esta fração hidrolisada do colágeno pode ser empregada como suplemento proteico, de forma isolada ou associada a outras proteínas. Desta forma, a gelatina é um ingrediente amplamente explorado para a obtenção de produtos dietéticos, de baixa caloria, sem colesterol e reduzido teor de lipídeos. Dentre as principais propriedades tecnológicas da gelatina em aplicações industriais, destacam-se: agente espessante, geleificante, estabilizante, surfactante (emulsificante e espumante), formador de filmes, para prevenção de sinérese e para dar cremosidade aos mais diferentes produtos (Furlan \& Boldrini, 2013).

Neste trabalho, objetivamos desidratar o resíduo de mosturação da cerveja e aplicá-lo na elaboração de barras de cereais, juntamente com a proteína hidrolisada de soja e a gelatina, avaliando as propriedades tecnológicas do produto através da Metodologia de Superfície de Resposta e otimizar a formulação.

\section{Metodologia}

Este trabalho consistiu em um estudo laboratorial e experimental com de análise quantitativa dos dados, sendo desenvolvido em etapas conforme proposto por Pereira, Shitsuka, Pereira, \& Shitsuka (2018).

\subsection{Matéria-prima}

O resíduo de mosturação da cerveja tipo IPA (India Pale Ale) foi doado pela cervejaria Diamantina (Diamantina, MG). A proteína hidrolisada de soja foi doada pela HT Nutri (Camaquã, RS). Os flocos de aveia, os flocos de arroz, os flocos de milho, o xarope de glicose, a margarina culinária (86 \% de lipídeos), o cloreto de sódio, a lecitina de soja e a gelatina foram adquiridos no comércio local (Diamantina, MG).

\subsection{Secagem do resíduo de mosturação}

O resíduo de mosturação foi submetido à secagem em três temperaturas $\left(40\right.$, 60 e $\left.80{ }^{\circ} \mathrm{C}\right)$ em estufa TE-394-1 (Tecnal, Piracicaba, Brasil) com circulação e renovação de ar constante igual a $1 \mathrm{~m} \cdot \mathrm{s}^{-1}$, objetivando uma umidade final inferior a $15 \%$, de acordo com metodologia proposta por (Schmiele et al., 2017b). Em triplicata para cada temperatura de secagem, uma amostra de $70 \mathrm{~g}$ do resíduo do mosturação foi submetido à secagem em formas retangulares de alumínio com $300 \mathrm{~mm}$ de comprimento e $80 \mathrm{~mm}$ de largura e área total de $0,024 \mathrm{~m}^{2}$, sendo pesadas em intervalos de $10 \mathrm{~min}$ na primeira hora e de $15 \mathrm{~min}$ 
nas $2 \mathrm{~h}$ subsequentes. Os dados experimentais avaliados foram a razão de umidade (RU) em função do tempo de secagem (h), a taxa de secagem em função da RU ( $\mathrm{kg}$ de água $/ \mathrm{kg}$ de sólido seco.m² ${ }^{2}$ ) e a velocidade média de secagem (kg de água/kg de sólido seco. $\mathrm{m}^{2} \mathrm{~s}$ ), conforme descrito por Silva (2020). A umidade do resíduo de mosturação foi determinada, em quadruplicata, pelo método 934.01 da Association of Official Analytical Chemists (AOAC, 2019).

\subsection{Formulação padrão e delineamento experimental dos ensaios}

A formulação padrão (baseada em Silva, Oliveira, Lopes, \& Pena, 2009) foi composta por uma mistura de flocos (flocos de aveia:flocos de arroz:flocos de milho na proporção de 70:25:05, respectivamente), correspondendo a 60 \% da formulação. Os demais $40 \%$ da formulação foram compostos por xarope de glicose: margarina culinária:lecitina de soja:cloreto de sódio na proporção de 93,5:5:1:0,5, respectivamente.

A avaliação do desempenho do resíduo da mosturação, da proteína hidrolisada de soja e da gelatina foi realizada através da Metodologia de Superfície de Resposta de três variáveis independentes, de acordo com a Tabela 1 (Rodrigues \& Iemma, 2014). Um modelo de regressão polinomial de segunda ordem foi estabelecido de acordo com a Equação 1. A mistura de flocos foi substituída pelo resíduo de mosturação e pela proteína hidrolisada de soja e o xarope de glicose foi substituído pela gelatina. A gelatina foi hidratada previamente na proporção de 1:3 (gelatina:água).

$$
Y=\beta_{0}+\beta_{1} x_{1}+\beta_{2} X_{2}+\beta_{3} X_{3}+\beta_{1} x_{1}^{2}+\beta_{2} x_{2}^{2}+\beta_{3} x_{3}^{2}+\beta_{12} x_{1} x_{2}+\beta_{13} X_{1} x_{3}+\beta_{23} X_{2} X_{3}+\varepsilon
$$

Onde: Y é a variável dependente; $\beta_{0}, \beta_{\mathrm{i}}, \beta_{\mathrm{ii}}$ e $\beta_{\mathrm{ij}}$ são as constantes dos termos de regressão linear, quadrático e de interação, respectivamente; $\mathrm{x}_{\mathrm{i}}$ e $\mathrm{x}_{\mathrm{j}}$ são os valores codificados das variáveis independentes; e $\varepsilon$ é o erro experimental. 
Tabela 1 - Níveis codificados e reais para a avaliação do desempenho do resíduo de mosturação, da proteína de soja e da razão gelatina:água no desenvolvimento da barra de cereais

\begin{tabular}{|c|c|c|c|c|c|c|c|c|c|}
\hline \multirow{3}{*}{ Ensaio } & \multicolumn{6}{|c|}{ Variáveis independentes } & \multirow{3}{*}{$\begin{array}{l}\text { Mistura } \\
\text { de flocos }\end{array}$} & \multirow{3}{*}{$\begin{array}{l}\text { Gelatina: } \\
\text { água }\end{array}$} & \multirow{3}{*}{$\begin{array}{l}\text { Xarope } \\
\text { de glicos }\end{array}$} \\
\hline & \multicolumn{3}{|c|}{ Níveis codificados } & \multicolumn{3}{|c|}{ Níveis reais } & & & \\
\hline & $\mathbf{x}_{1}$ & $\mathbf{x}_{2}$ & $\mathbf{x}_{3}$ & $\overline{\mathbf{X}_{1}}$ & $\overline{\mathbf{X}_{2}}$ & $\overline{\mathbf{X}_{3}}$ & & & \\
\hline 1 & -1 & -1 & -1 & 10 & 4 & 20 & 86 & $5,0: 15,0$ & 80 \\
\hline 2 & +1 & -1 & -1 & 40 & 4 & 20 & 56 & $5,0: 15,0$ & 80 \\
\hline 3 & -1 & +1 & -1 & 10 & 16 & 20 & 74 & $5,0: 15,0$ & 80 \\
\hline 4 & +1 & +1 & -1 & 40 & 16 & 20 & 44 & $5,0: 15,0$ & 80 \\
\hline 5 & -1 & -1 & +1 & 10 & 4 & 80 & 86 & $20,0: 60,0$ & 20 \\
\hline 6 & +1 & -1 & +1 & 40 & 4 & 80 & 56 & $20,0: 60,0$ & 20 \\
\hline 7 & -1 & +1 & +1 & 10 & 16 & 80 & 74 & $20,0: 60,0$ & 20 \\
\hline 8 & +1 & +1 & +1 & 40 & 16 & 80 & 44 & $20,0: 60,0$ & 20 \\
\hline 9 & $-1,68$ & 0 & 0 & 0 & 10 & 50 & 90 & $12,5: 37,5$ & 50 \\
\hline 10 & $+1,68$ & 0 & 0 & 50 & 10 & 50 & 40 & $12,5: 37,5$ & 50 \\
\hline 11 & 0 & $-1,68$ & 0 & 25 & 0 & 50 & 75 & $12,5: 37,5$ & 50 \\
\hline 12 & 0 & $+1,68$ & 0 & 25 & 20 & 50 & 55 & $12,5: 37,5$ & 50 \\
\hline 13 & 0 & 0 & $-1,68$ & 25 & 10 & 0 & 65 & $0,0: 0,0$ & 100 \\
\hline 14 & 0 & 0 & $+1,68$ & 25 & 10 & 100 & 65 & $25,0: 75,0$ & 0 \\
\hline 15 & 0 & 0 & 0 & 25 & 10 & 50 & 65 & $12,5: 37,5$ & 50 \\
\hline 16 & 0 & 0 & 0 & 25 & 10 & 50 & 65 & $12,5: 37,5$ & 50 \\
\hline 17 & 0 & 0 & 0 & 25 & 10 & 50 & 65 & $12,5: 37,5$ & 50 \\
\hline 18 & 0 & 0 & 0 & 25 & 10 & 50 & 65 & $12,5: 37,5$ & 50 \\
\hline Padrão & - & - & - & - & - & - & 100 & - & 100 \\
\hline
\end{tabular}

Onde: $\mathrm{x}_{1}$ e $\mathrm{X}_{1}=$ Resíduo de mosturação; $\mathrm{x}_{2}$ e $\mathrm{X}_{2}=$ proteína de soja; $\mathrm{x}_{3}$ e $\mathrm{X}_{3}=$ razão gelatina:água. Fonte: Autores (2022).

\subsection{Processamento}

O fluxograma geral para a obtenção do resíduo de mosturação desidratado e a elaboração das barras de cereais está apresentado na Figura 1. Inicialmente, o xarope de glicose, a margarina culinária, a lecitina de soja, o cloreto de sódio, a gelatina e a água foram aquecidos até $80{ }^{\circ} \mathrm{C}$. Em seguida, o restante dos ingredientes foram incorporados e homogeneizados manualmente. A massa foi depositada em forma retangular medindo $170 \times 80 \times 13 \mathrm{~mm}$ (comprimento, largura, espessura) e compactada manualmente com auxílio de um rolo de polietileno até enchimento total da forma. As barras de cereais foram 
cortadas com largura de $\sim 28-30 \mathrm{~mm}$ com auxílio de uma faca, embaladas em papel manteiga e acondicionadas a $7{ }^{\circ} \mathrm{C}$ em câmara fria (overnight) em embalagem de polietileno de alta densidade. No dia seguinte, as amostras foram equilibradas à temperatura ambiente por $2 \mathrm{~h}$ antes das análises.

Figura 1 - Fluxograma geral para obtenção do resíduo de mosturação desidratado e elaboração das barras de cereais

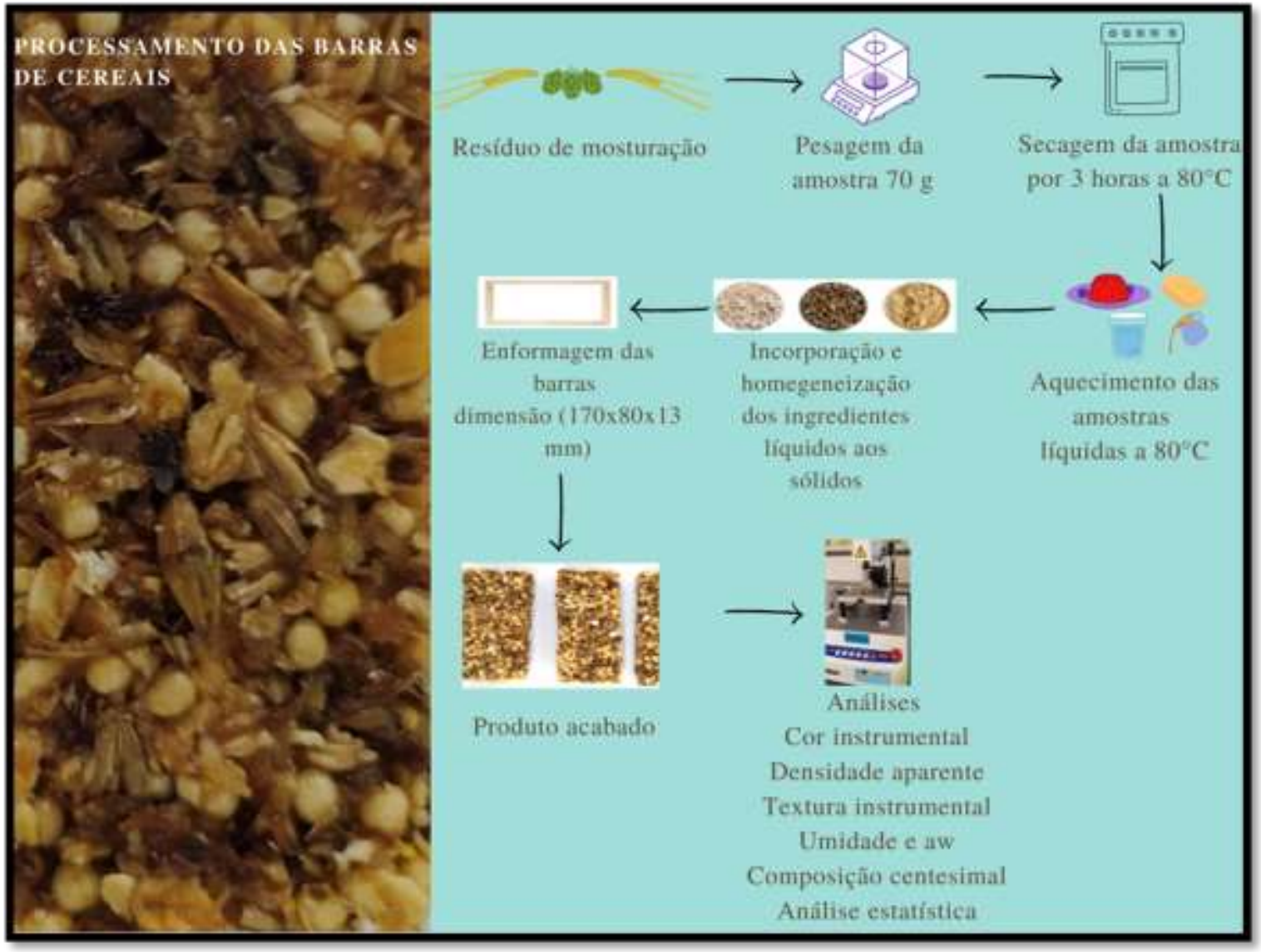

Fonte: Autores (2022).

\subsection{Cor instrumental}

A cor instrumental foi determinada em espectrofotômetro CM-5Konica (Minolta, Chiyoda, Japão) avaliando-se o sistema CIE- $L^{*} a^{*} b^{*}$ e a variação de cor ( $\Delta \mathrm{E}$ - obtido através da Equação 2), com três repetições. As condições do equipamento foram configuradas em: iluminante D65, ângulo de observação de $10^{\circ}$ e calibração no modo RSIN (Reflectance Specular Included), conforme descrito por Silva, Rosa, Neves, Leoro, \& Schmiele (2021).

$$
\Delta \mathrm{E}=\left[\left(\Delta L^{*}\right)^{2}+\left(\Delta a^{*}\right)^{2}+\left(\Delta b^{*}\right)^{2}\right]^{0,5}
$$

\subsection{Densidade aparente}

A densidade aparente foi avaliada seguindo metodologia descrita por Gibelato et al. (2016), com modificações. Três barras de cereais de cada ensaio foram medidas com o paquímetro óptico profissional 150 mm (Western, Suzhou, China) registrando-se o comprimento, a largura e a espessura. As barras foram pesadas em balança analítica AUY220 (Shimadzu, Tokyo, Japão) e a densidade aparente dada pela razão entre massa da amostra (mg) pelo produto das dimensões (mm ${ }^{3}$ ). Os resultados foram expressos em mg. $\mathrm{mm}^{3}$. 


\subsection{Textura instrumental}

As barras de cereais foram avaliadas de acordo com a fraturabilidade e a força de cisalhamento em texturômetroTA.XT Plus (Stable Micro Systems, Halsemere, Austrália). As condições de teste para a fraturabilidade foram: probe3-Point Bending Rig (HDP/3PB), velocidades de teste (1,0 mm/s), distância (10 mm) no modo compressão e limiar de força de 0,049 N. Para a análise de força de cisalhamento foi utilizada a plataforma HDP/90 e probe Warner Blatzer Knife Blade de $30 \mathrm{~mm}$, com teste em modo de compressão, força de teste $(0,5 \mathrm{~mm} / \mathrm{s})$ e pós-teste $(2,0 \mathrm{~mm} / \mathrm{s})$, altura do probe $(18 \mathrm{~mm})$, distância $(16 \mathrm{~mm})$ e limiar de força $(0,049 \mathrm{~N})$. As análises foram realizadas com 6 repetições para a fraturabilidade e com 10 repetições para a força de cisalhamento e os resultados expressos em $\mathrm{N}$.

\subsection{Umidade e atividade de água}

A umidade das barras de cereais foi determinada de acordo com o método 934.01 (AOAC, 2019) e os resultados expressos em \%. A medida de atividade de água foi realizada em higrômetro Aqualab ${ }^{\circledR}$ 4TE Duo (Decagon, Pullman, Estados Unidos), de acordo com Silva et al. (2009). Ambas as análises foram realizadas em triplicata.

\subsection{Composição centesimal e valor calórico total}

A composição centesimal da amostra padrão e do ponto otimizado foi determinada em relação à umidade (método $44-$ 15.02), cinzas (método 08-01.01), proteínas (método 46-13.01; N=6,25) e lipídios (método 30-25.01) (AACCI, 2010). Os carboidratos digestíveis compostos por açúcares disponíveis e o amido foram analisados pelo método 982.14 e a fibra alimentar total foi quantificada pelo método 978.10 (AOAC, 2019). Todas as análises foram realizadas em triplicata. O valor calórico total foi calculado considerando o método de conversão de Atwater, conforme descrito por Souza e Schmiele (2021). Para o valor calórico total foram considerados os valores de conversão de $4 \mathrm{kcal.g} \mathrm{g}^{-1}$ para proteínas e carboidratos digeríveis (açúcares e amido) e $9 \mathrm{kcal}_{\mathrm{g}}{ }^{-1}$ para lipídeos (Simanca-Sotelo, Paula, Domínguez-Anaya, Pastrana-Puche, \& ÁlvarezBadel, 2021).

\subsection{Análise estatística}

Os resultados avaliados durante a cinética de secagem e a cor instrumental das matérias-primas foram avaliados através de análise de variância (ANOVA) e, quando observadas diferenças estatisticamente significativas, o teste de Tukey foi utilizado para a comparação das médias $(\mathrm{p}<0,05)$. Os dados obtidos nos ensaios do delineamento experimental foram avaliados através de Metodologia de Superfície de Resposta para cálculo dos coeficientes de regressão e ANOVA com nível de significância de 10 \%. Para o presente trabalho foi adotado coeficiente de regressão mínimo $\left(\mathrm{R}^{2}\right)$ da ANOVA de 0,80 . O ponto otimizado foi determinado através de metodologia proposta por Derringer \& Suich (1980). Os dados da composição centesimal e do valor calórico total foram avaliados pelo teste $t$-Student $(\mathrm{p}<0,05)$. 


\section{Resultados e discussão}

\subsection{Cinética de secagem do resíduo de mosturação}

O resíduo de mosturação apresentou 73,68 \% de umidade inicial (Figura 2). Com maiores temperaturas de secagem houve uma redução significativa para a umidade final após 3 horas de secagem $(\mathrm{p}<0,001)$. Da mesma forma, a velocidade média de secagem também apresentou influência significativa $(\mathrm{p}<0,001)$ com o aumento da temperatura de secagem. No entanto, observou-se que a diferença entre a velocidade média de secagem da amostra desidratada a 40 e $60{ }^{\circ} \mathrm{C}(0,49 \mathrm{~kg}$ de água/kg de sólido seco. $\left.\mathrm{m}^{2} \mathrm{~s}\right)$ foi 10 vezes superior em relação às temperaturas de secagem de 60 e $80{ }^{\circ} \mathrm{C}(0,05 \mathrm{~kg}$ de água $/ \mathrm{kg}$ de sólido seco. $\mathrm{m}^{2} \mathrm{~s}$ ). Conforme observado na Figura 3, o tempo de secagem de $3 \mathrm{~h}$ a $40{ }^{\circ} \mathrm{C}$ não foi o suficiente para atingir a umidade máxima de $15 \%$. Entretanto, em torno de $140 \mathrm{~min}$ para $60{ }^{\circ} \mathrm{C}$ e $85 \mathrm{~min}$ para $80{ }^{\circ} \mathrm{C}$ foram o suficiente para que as farinhas apresentem o limite de umidade estipulado pela legislação para armazenamento e comercialização de farinhas (Brasil, 2005).

Figura 2 - Razão de umidade em função do tempo de secagem do resíduo de mosturação da cerveja para as temperaturas de 40,60 e $80^{\circ} \mathrm{C}$

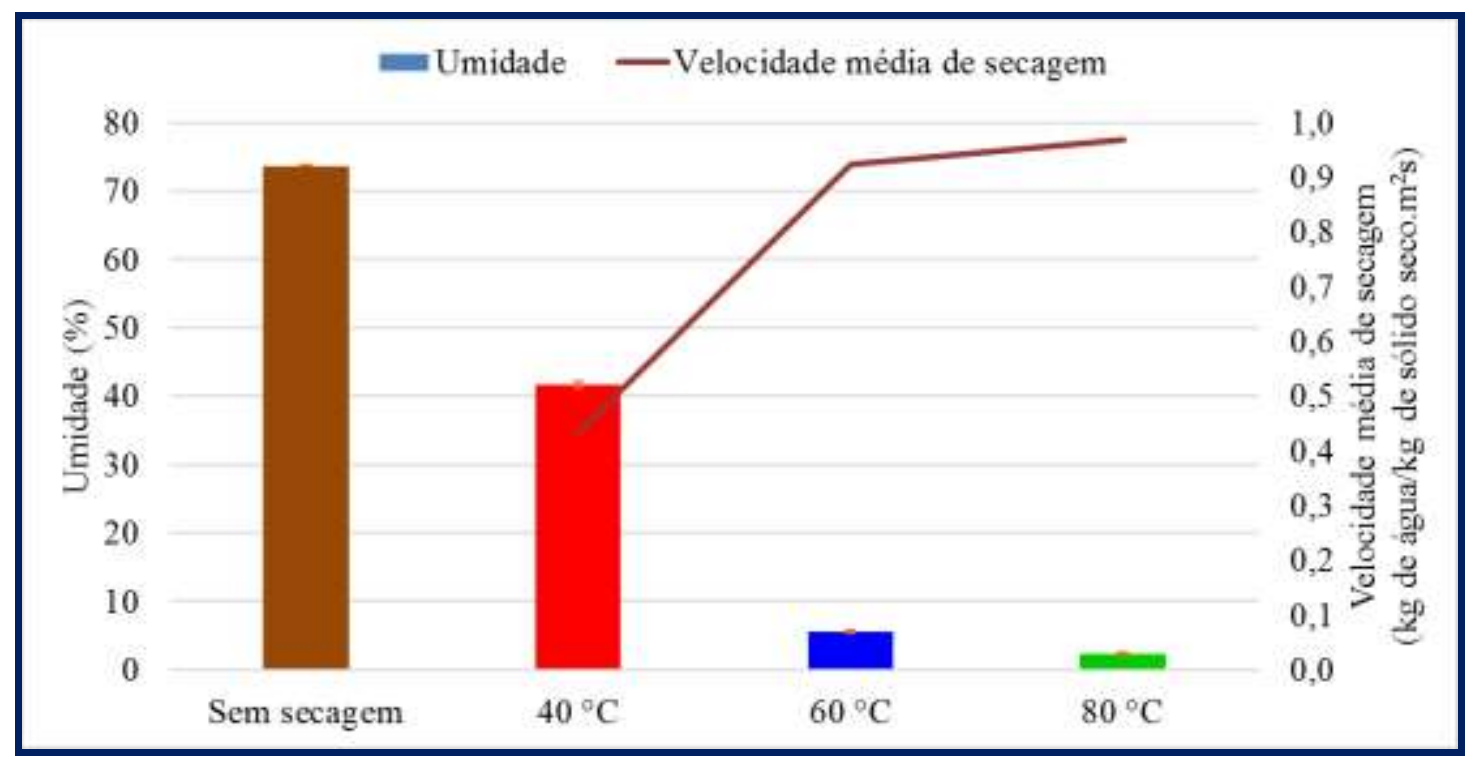

Fonte: Autores (2022).

A cinética de secagem apresenta um perfil típico com três períodos característicos, sendo o período em regime permanente, período a taxa constante e período a taxa decrescente (Das \& Das, 2021). De acordo com a Figura 4, as temperaturas de secagem a 60 e $80^{\circ} \mathrm{C}$ apresentaram os períodos de regime não permanente e o período de taxa decrescente, enquanto a amostra desidratada a $40{ }^{\circ} \mathrm{C}$ apresentou somente o período de taxa decrescente. Em nenhuma das curvas da taxa de secagem foi observado o período de taxa constante, ocorrendo a ambientação do material à temperatura de secagem, seguido pelo período de taxa decrescente de desidratação. De acordo com Silva (2020), condições operacionais de secagem podem fazer com a taxa de evaporação da água da superfície do material ao ambiente seja superior que a transferência da umidade do interior do produto à superfície. Materiais fibrosos, como o caso do resíduo de mosturação da cerveja, e com granulometria desuniforme tendem a apresentar longos tempos de secagem em função da formação de uma crosta impermeável na camada superior quando realizados processos de secagem em batelada. Segundo Damodaran e Parking (2017), este fenômeno resulta na diminuição da difusão interna e o efeito capilar (encolhimentos dos poros) para a remoção da água. 
Em alguns estudos observou-se efeitos parecidos com o efeito da temperatura na cinética de secagem de resíduo sólido de oliva (Goula, Chasekioglou, \& Lazarides, 2015), de resíduo de mosturação de cerveja (Schmiele et al., 2017b), de semente de maracujá (André, Nascimento, Almeida, Santos, \& Almeida, 2018), de coproduto semissólido de extração de azeite de oliva (Silva, 2020) e de kiwi (Prithani \& Dash, 2020).

Figura 3 - Razão de umidade em função do tempo de secagem do resíduo de mosturação da cerveja para as temperaturas de 40,60 e $80^{\circ} \mathrm{C}$

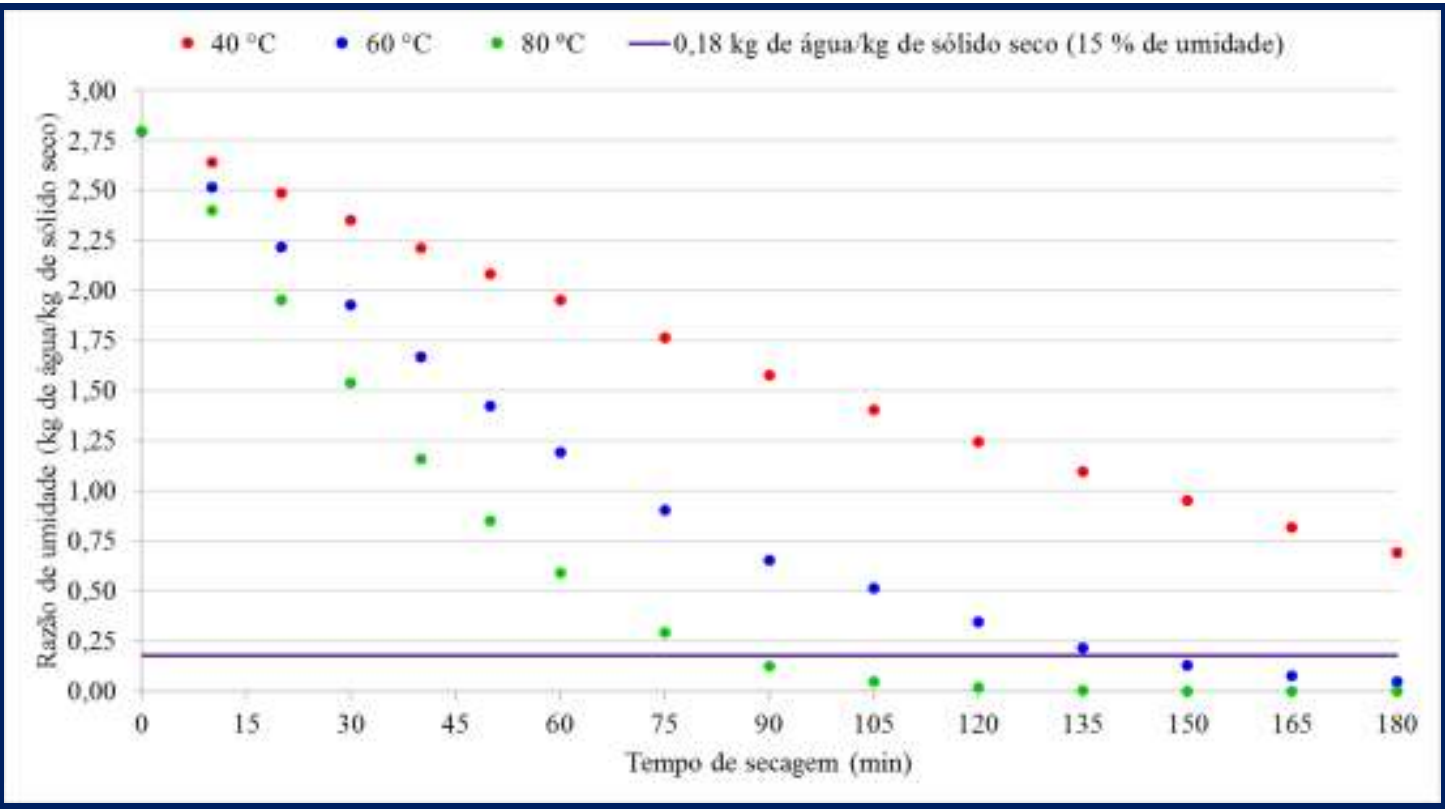

A linha roxa corresponde a quantidade máxima de água remanescente no produto para atingir a umidade máxima de $15 \%$ para a conservação da farinha. Fonte: Autores (2022).

Figura 4 - Taxa de secagem do resíduo de mosturação da cerveja para as temperaturas de 40,60 e $80{ }^{\circ} \mathrm{C}$

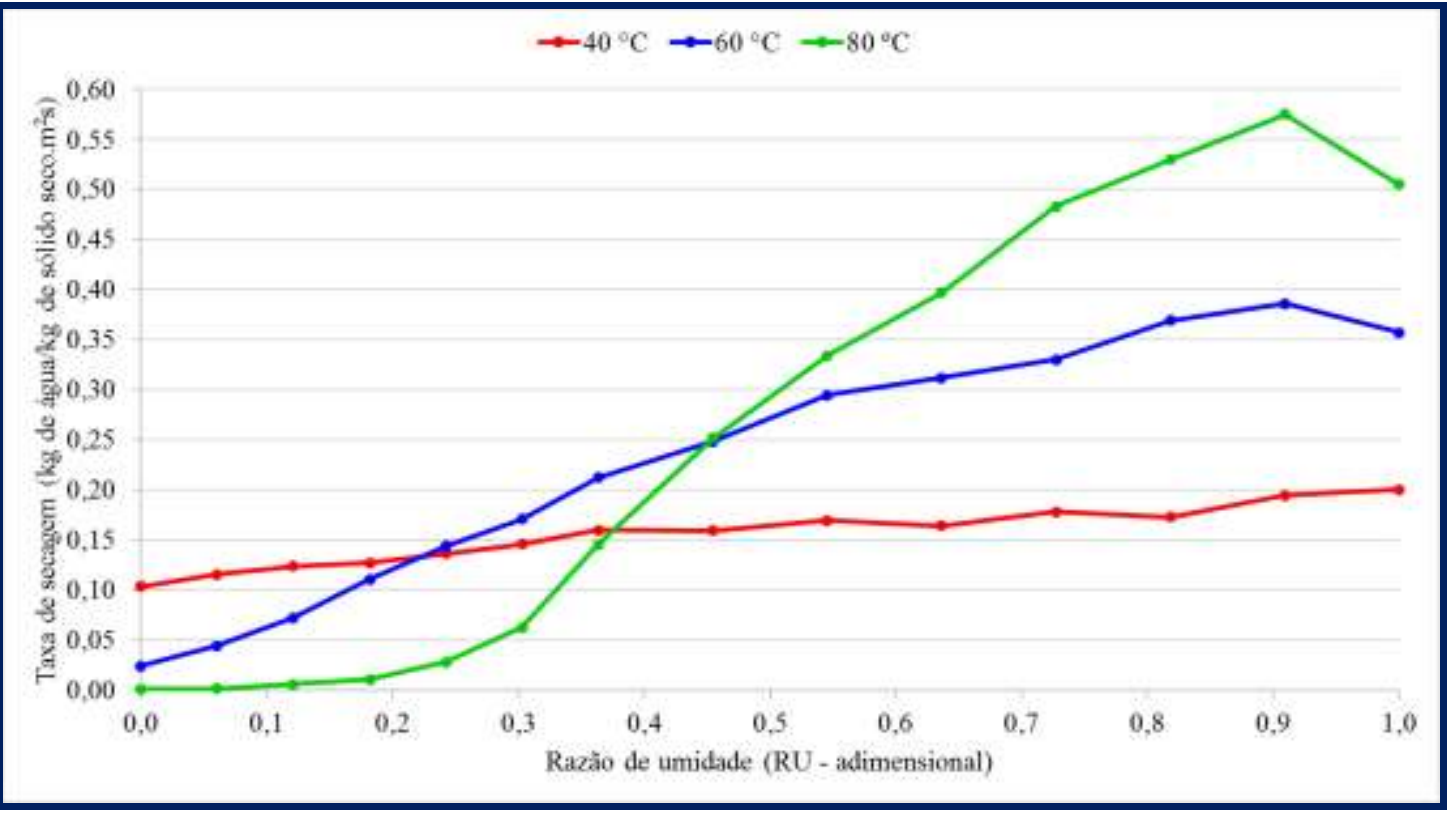

Fonte: Autores (2022). 
Ao comparar taxa crítica de secagem a temperatura constante, observou-se que a $80{ }^{\circ} \mathrm{C}$, a remoção máxima de água foi de $0,58 \mathrm{~kg}$ de água $/ \mathrm{kg}$ de sólido $\mathrm{seco.} \mathrm{m}^{2} \mathrm{~s}$, sendo 0,49 vezes superior a secagem a $60{ }^{\circ} \mathrm{C}(0,39 \mathrm{~kg}$ de água/ $\mathrm{kg}$ de sólido seco.m² ${ }^{2}$ ). Desta forma, a melhor temperatura de secagem foi definida em $80{ }^{\circ} \mathrm{C}$ para a produção de farinha de resíduo de mosturação de cerveja e potencial aplicação em alimentos, nas condições testadas em nosso experimento.

\subsection{Variáveis dependentes das barras de cereais}

Os resultados obtidos através do delineamento experimental e amostra padrão para as análises de cor instrumental (parâmetros $L^{*}, a^{*}, b^{*}, \Delta \mathrm{E}$ ), densidade aparente e textura instrumental (fraturabilidade e força de cisalhamento) estão apresentados na Tabela 2 e para umidade e atividade de água estão expostos na Figura 5. Na Tabela 3 estão apresentados os modelos matemáticos preditivos e os resultados obtidos para a análise de variância das variáveis dependentes estatisticamente significativas $(\mathrm{p}<0,10)$.

Tabela 2 - Resultados experimentais para a cor instrumental (parâmetros $L^{*}, a^{*}, b^{*}$ e $\left.\Delta \mathrm{E}\right)$, a densidade aparente $\left(\mathrm{mg}^{\mathrm{m}} \mathrm{mm}{ }^{-3}\right.$ ) e a textura instrumental avaliando-se a força de cisalhamento $(\mathrm{N})$ e a fraturabilidade $(\mathrm{N})$ das barras de cereais obtidas pelo Delineamento Composto Central Rotacional e da amostra padrão.

\begin{tabular}{|c|c|c|c|c|c|c|c|}
\hline \multirow{2}{*}{ Ensaio } & \multicolumn{4}{|c|}{ Cor instrumental $(n=3)$} & \multirow{2}{*}{$\begin{array}{l}\text { Densidade } \\
\text { aparente } \\
(n=3)\end{array}$} & \multirow{2}{*}{$\begin{array}{l}\text { Fraturabi- } \\
\text { lidade }(n=6)\end{array}$} & \multirow{2}{*}{$\begin{array}{l}\text { Força de } \\
\text { cisalhamento } \\
(\mathrm{n}=10)\end{array}$} \\
\hline & $L^{*}$ & $a^{*}$ & $b^{*}$ & $\Delta \mathbf{E}$ & & & \\
\hline 1 & $56,24 \pm 0,75$ & $0,71 \pm 0,01$ & $24,22 \pm 0,92$ & $9,07 \pm 0,67$ & $0,71 \pm 0,01$ & $25,44 \pm 2,09$ & $169 \pm 17$ \\
\hline 2 & $45,92 \pm 0,60$ & $5,62 \pm 0,06$ & $19,42 \pm 0,03$ & $19,81 \pm 0,58$ & $0,60 \pm 0,03$ & $18,16 \pm 1,69$ & $141 \pm 17$ \\
\hline 3 & $50,13 \pm 1,62$ & $9,90 \pm 0,11$ & $26,41 \pm 0,87$ & $15,93 \pm 1,40$ & $0,84 \pm 0,02$ & $64,33 \pm 6,35$ & $223 \pm 35$ \\
\hline 4 & $43,75 \pm 1,91$ & $7,22 \pm 0,26$ & $21,06 \pm 1,03$ & $21,73 \pm 2,00$ & $0,63 \pm 0,04$ & $33,03 \pm 3,96$ & $193 \pm 54$ \\
\hline 5 & $54,66 \pm 1,53$ & $6,47 \pm 0,26$ & $23,99 \pm 1,02$ & $9,56 \pm 0,20$ & $0,76 \pm 0,02$ & $112,73 \pm 6,99$ & $250 \pm 31$ \\
\hline 6 & $44,84 \pm 1,45$ & $5,50 \pm 0,13$ & $18,59 \pm 0,62$ & $21,07 \pm 1,56$ & $0,55 \pm 0,02$ & $49,47 \pm 3,95$ & $132 \pm 21$ \\
\hline 7 & $48,20 \pm 1,30$ & $9,49 \pm 0,22$ & $26,07 \pm 0,61$ & $17,61 \pm 1,18$ & $0,80 \pm 0,01$ & $141,10 \pm 5,67$ & $261 \pm 29$ \\
\hline 8 & $45,37 \pm 1,80$ & $8,17 \pm 0,30$ & $22,6 \pm 0,69$ & $20,08 \pm 1,81$ & $0,70 \pm 0,03$ & $106,27 \pm 5,92$ & $251 \pm 28$ \\
\hline 9 & $56,66 \pm 0,78$ & $9,46 \pm 0,06$ & $27,75 \pm 0,24$ & $10,16 \pm 0,56$ & $0,87 \pm 0,03$ & $174,60 \pm 9,20$ & $240 \pm 38$ \\
\hline 10 & $41,46 \pm 1,82$ & $5,89 \pm 0,14$ & $17,72 \pm 0,57$ & $24,55 \pm 1,90$ & $0,63 \pm 0,02$ & $47,14 \pm 6,28$ & $158 \pm 19$ \\
\hline 11 & $53,83 \pm 1,00$ & $4,66 \pm 0,34$ & $19,26 \pm 1,39$ & $12,40 \pm 1,29$ & $0,69 \pm 0,01$ & $100,59 \pm 7,97$ & $208 \pm 20$ \\
\hline 12 & $44,13 \pm 1,52$ & $8,84 \pm 0,26$ & $22,75 \pm 0,48$ & $21,37 \pm 1,53$ & $0,86 \pm 0,02$ & $172,91 \pm 12,95$ & $333 \pm 28$ \\
\hline 13 & $49,86 \pm 1,35$ & $6,93 \pm 0,04$ & $22,64 \pm 0,55$ & $15,47 \pm 1,39$ & $0,70 \pm 0,01$ & $57,60 \pm 6,52$ & $288 \pm 57$ \\
\hline 14 & $46,57 \pm 0,67$ & $7,67 \pm 0,25$ & $22,91 \pm 0,53$ & $18,79 \pm 0,69$ & $0,72 \pm 0,04$ & $85,14 \pm 9,19$ & $218 \pm 34$ \\
\hline 15 & $48,49 \pm 1,81$ & $6,86 \pm 0,17$ & $21,61 \pm 0,87$ & $16,95 \pm 1,90$ & $0,72 \pm 0,03$ & $142,68 \pm 11,05$ & $260 \pm 30$ \\
\hline 16 & $49,87 \pm 0,53$ & $7,04 \pm 0,25$ & $22,44 \pm 0,10$ & $15,48 \pm 0,53$ & $0,72 \pm 0,01$ & $144,95 \pm 16,44$ & $235 \pm 30$ \\
\hline 17 & $49,61 \pm 1,58$ & $7,13 \pm 0,21$ & $21,84 \pm 0,24$ & $15,85 \pm 1,61$ & $0,70 \pm 0,03$ & $143,22 \pm 6,65$ & $249 \pm 15$ \\
\hline 18 & $46,66 \pm 0,98$ & $7,03 \pm 0,48$ & $21,12 \pm 0,85$ & $18,84 \pm 1,03$ & $0,71 \pm 0,02$ & $92,76 \pm 7,29$ & $251 \pm 40$ \\
\hline Padrão & $63,86 \pm 0,35$ & $5,46 \pm 0,11$ & $24,01 \pm 0,16$ & - & $0,71 \pm 0,01$ & $100,69 \pm 10,43$ & $323 \pm 41$ \\
\hline
\end{tabular}

Valores correspondentes à média aritmética \pm desvio padrão. Fonte: Autores (2022). 
Figura 5 - Resultados experimentais para a atividade de água e a umidade das barras de cereais obtidas pelo Delineamento Composto Central Rotacional e da amostra padrão (P).

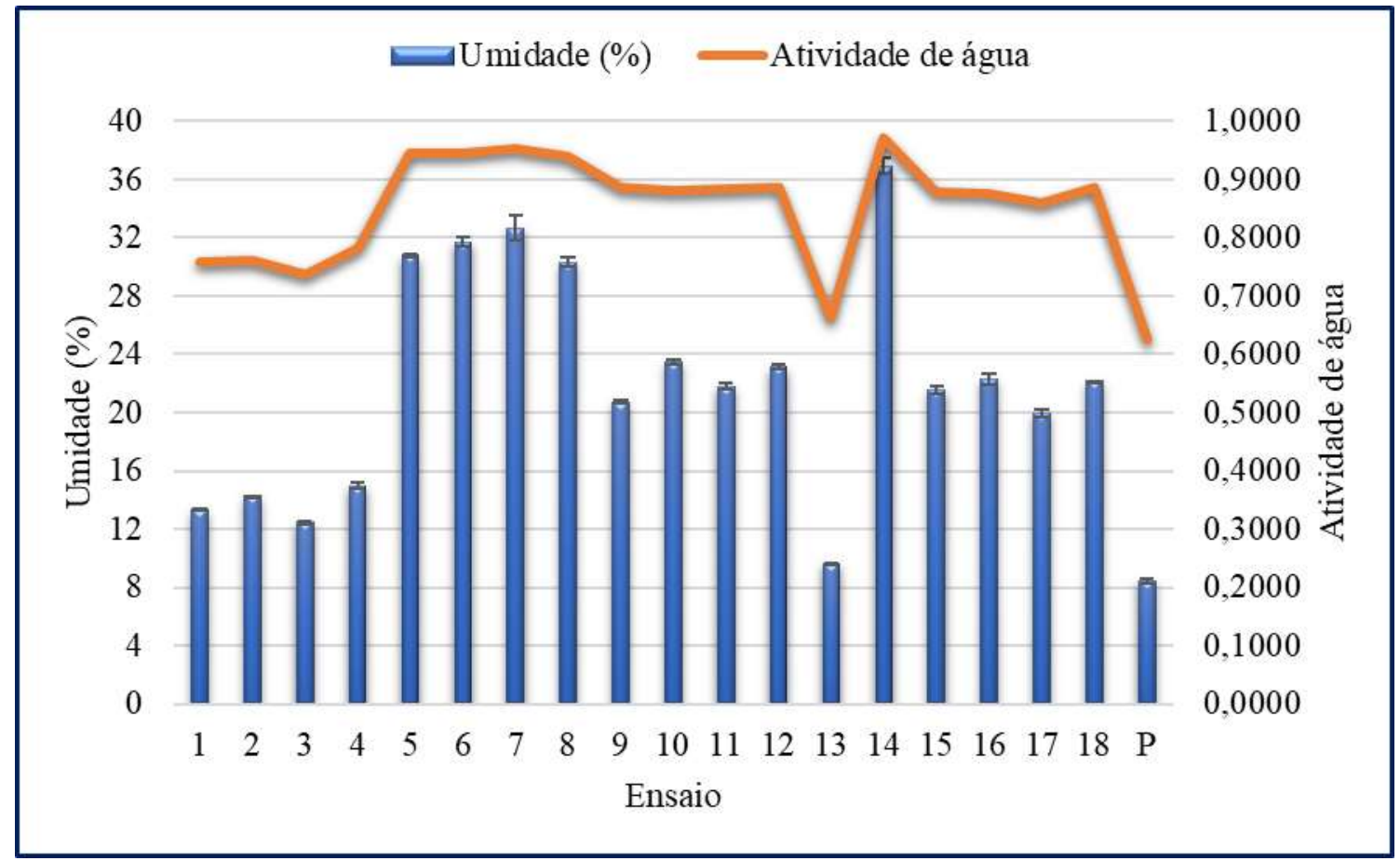

Fonte: Autores (2022).

Tabela 3 - Modelos matemáticos para as variáveis dependentes estatisticamente significativas $(\mathrm{p}<0,10)$ para elaboração da barra de cereais com aplicação do resíduo de mosturação, proteína hidrolisada de soja e razão gelatina:água, conforme o Delineamento Composto Central Rotacional.

\begin{tabular}{llll}
\hline Variável dependente & Modelo matemático preditivo & $\mathbf{R}^{2}(\%)$ & p-valor \\
\hline$L^{*}$ & $48,68-4,02 \mathrm{x}_{1}-2,23 \mathrm{x}_{2}-0,62 \mathrm{x}_{3}+1,37 \mathrm{x}_{1} \mathrm{x}_{2}$ & 94,24 & $<0,001$ \\
& $7,01-0,87 \mathrm{x}_{1}+1,30 \mathrm{x}_{2}+0,12 \mathrm{x}_{3}+0,26 \mathrm{x}_{1}{ }^{2}-0,07 \mathrm{x}_{2}{ }^{2}+0,12 \mathrm{x}_{3}{ }^{2}$ & 97,71 & $<0,001$ \\
$a^{*}$ & $-0,27 \mathrm{x}_{1} \mathrm{x}_{2}+0,16 \mathrm{x}_{1} \mathrm{x}_{3}+0,08 \mathrm{x}_{2} \mathrm{x}_{3}$ & 93,93 & $<0,001$ \\
$b^{*}$ & $21,65-2,57 \mathrm{x}_{1}+1,25 \mathrm{x}_{2}+0,50 \mathrm{x}_{1}{ }^{2}+0,51 \mathrm{x}_{3}{ }^{2}$ & 95,51 & $<0,001$ \\
Variação de cor $(\Delta \mathrm{E})$ & $16,93+4,01 \mathrm{x}_{1}+2,27 \mathrm{x}_{2}+0,54 \mathrm{x}_{3}-1,75 \mathrm{x}_{1} \mathrm{x}_{2}$ & 89,02 & $<0,001$ \\
Densidade aparente $\left(\mathrm{mg} \cdot \mathrm{mm}^{-3}\right)$ & $0,72-0,08 \mathrm{x}_{1}+0,05 \mathrm{x}_{2}+0,01 \mathrm{x}_{3}+0,01 \mathrm{x}_{2}{ }^{2}-0,01 \mathrm{x}_{3}{ }^{2}$ & & \\
& $145,38-25,71 \mathrm{x}_{1}+19,09 \mathrm{x}_{2}+23,08 \mathrm{x}_{3}-19,25 \mathrm{x}_{1}{ }^{2}-10,08 \mathrm{x}_{2}{ }^{2}$ & 82,68 & 0,011 \\
Fraturabilidade $(\mathrm{N})$ & $-3,24 \mathrm{x}_{3}{ }^{2}-7,44 \mathrm{x}_{1} \mathrm{x}_{3}+3,93 \mathrm{x}_{2} \mathrm{x}_{3}$ & & \\
& $0,8777+0,0928 \mathrm{x}_{3}-0,0229 \mathrm{x}_{3}{ }^{2}-0,0073 \mathrm{x}_{1} \mathrm{x}_{3}$ & 99,00 & $<0,001$ \\
Atividade de água & $21,94+0,49 \mathrm{x}_{1}+8,52 \mathrm{x}_{3}+0,52 \mathrm{x}_{3}{ }^{2}-0,61 \mathrm{x}_{1} \mathrm{x}_{3}$ & 98,85 & $<0,001$ \\
Umidade $(\%)$ & & &
\end{tabular}

$\mathrm{x}_{1}, \mathrm{x}_{2}$ e $\mathrm{x}_{3}$ correspondem aos valores codificados de resíduo de mosturação, proteína hidrolisada de soja e razão gelatina:água, respectivamente; $\mathrm{R}^{2}$ é o coeficiente de determinação da análise de variância. Fonte: Autores (2022).

\subsubsection{Cor instrumental}

Os dados para a luminosidade das amostras variaram entre 41,46 e 56,66 para os ensaios (Tabela 2), sendo que 94,24\% dos dados foram explicados pelo modelo matemático, com razão de $\mathrm{F}_{\text {cal }} / \mathrm{F}_{\text {tab }(4 ; 13 ; 0,10)}=21,89$ e p-valor $<0,001$, de acordo com a ANOVA. Os principais efeitos que promoveram a redução nos valores de $L^{*}$ foram os termos lineares do resíduo 
de mosturação $\left(\beta_{1}=-4,02 ; \mathrm{p}<0,001\right)$ e de proteína hidrolisada de soja $\left(\beta_{2}=-2,23, \mathrm{p}<0,001\right)$ (Tabela 3). De acordo com as curvas de contorno (Figura 6), observou-se que com os incrementos das variáveis independentes ocorreu a produção de barras de cereais mais escuras, característico do uso de fibras alimentares oriundas de farelos de cereais e pela coloração das fontes de proteínas adicionadas. Este comportamento é explicado quando compararmos os valores de $L^{*}$ dos ensaios com a amostra padrão, o qual foi superior $(63,68)$ (Tabela 2). O efeito de escurecimento na coloração das amostras foi atenuado pelo uso combinado entre o resíduo de mosturação e a proteína hidrolisada de soja $\left(\beta_{12}=1,37 ; \mathrm{p}<0,007\right)$ (Tabela 3).

A tonalidade avermelhada (parâmetro $a^{*}$ com valores positivos) foi observada nos ensaios do delineamento experimental, bem como na amostra padrão. Os dados dos ensaios variaram entre 0,71 e 9,90, sendo que a amostra controle padrão apresentou valor intermediário $(5,46)$ (Tabela 2). A ANOVA apresentou um coeficiente de determinação do modelo matemático de $97,71 \%, \mathrm{~F}_{\mathrm{cal}} / \mathrm{Ftab}_{(9 ; 8 ; 0,10)}=15,53$ e p-valor $<0,001$. Os valores do parâmetro $a^{*}$ apresentaram uma leve diminuição com a incorporação do resíduo de mosturação $\left(\beta_{1}=-0,87 ; \mathrm{p}<0,001\right)$ e aumento com a aplicação do hidrolisado proteico de soja $\left(\beta_{2}=1,30 ; \mathrm{p}<0,001\right)$ (Tabela 3), ambos nos níveis fatoriais. Além disso, o uso da gelatina hidratada nos níveis fatoriais e axiais ou combinada com o resíduo de mosturação resultou em maiores valores de $a^{*}$. De acordo com a Figura 6, menores níveis de proteína hidrolisada de soja e gelatina hidratada e maiores teores de resíduo de mosturação resultam em barras de cereais que tendem a tonalidade cinza (valores de $a^{*}$ próximos a zero).

Os valores do parâmetro $b^{*}$ foram entre 17,72 e 26,41, com valores médios de 21,65 (Tabela 2). Os dados experimentais foram explicados por $93,93 \%$ do modelo matemático preditivo, com razão $\mathrm{F}_{\text {cal }} / \mathrm{F}_{\text {tab }}(4 ; 13 ; 0,10)=15,53$ e $\mathrm{p}$-valor $<0,001$. Os termos lineares do resíduo de mosturação $\left(\beta_{1}=-2,57\right.$; $\left.\mathrm{p}<0,001\right)$ e da proteína hidrolisada de soja $\left(\beta_{2}=1,25 ; \mathrm{p}=0,003\right)$ apresentaram os principais efeitos sobre a variável dependente em estudo (Tabela 3). Com a aplicação das variáveis independentes foram obtidas barras de cereais com valores de $b^{*}$ maiores e menores que a amostra padrão (24,01) (Tabela 2). As curvas de contorno (Figura 6) observou-que que as barras contendo maiores teores de resíduo de mosturação, menores níveis de proteína hidrolisada de soja e níveis intermediários (próximos ao ponto central) de razão gelatina:água apresentaram os menores valores de $b^{*}$.

De modo geral, observou-se que os ensaios do delineamento experimental apresentaram aparência mais escura e com tonalidades levemente acinzentadas, o que pode ser observado visualmente na Figura 7. A coloração com tonalidades escuras e cinzas remetem indiretamente ao consumo de alimentos integrais a base de cereais por parte dos consumidores e estão relacionados à alimentos integrais promotores de saúde, principalmente associados a alimentos me menores índices glicêmicos, maiores teores de fibras alimentares e minerais (Jones, García, \& Braun, 2020). Efeitos semelhantes foram obtidos por Stelick, Sogari, Rodolfi, Dando, \& Paciulli (2021) ao estudar a aplicação de resíduo de mosturação em barras de cereais. No entanto, a principal alteração na coloração é oriunda da Reação de Maillard durante a fase de desidratação do co-produto em função do alto teor proteico (Petrovic et al., 2017). Desta forma, os valores obtidos para a variação de cor das barras de cereais podem ser vantajosos e sensorialmente promissores. Os dados obtidos para o $\Delta \mathrm{E}$ variaram de 9,07 a 24,55 (Tabela 2), sendo os dados experimentais explicados por 95,51\% através do modelo matemático preditivo, considerando que a ANOVA apresentou valores complementares de $\mathrm{F}_{\mathrm{cal}} / \mathrm{F}_{\text {tab (4;13;0,10) }}=28,42$ e p-valor $<0,001$. Os maiores efeitos foram observados pelos termos lineares do resíduo de mosturação $\left(\beta_{1}=4,01 ; \mathrm{p}<0,001\right)$ e da proteína hidrolisada de soja $\left(\beta_{2}=2,27 ; \mathrm{p}=0,003\right)$ (Tabela 3). Segundo Mokrzycki \& Tatol (2011), valores de $\Delta \mathrm{E}$ superiores a 5,0 indicam que qualquer consumidor pode identificar claramente cores distintas entre os alimentos. 
Research, Society and Development, v. 11, n. 2, e8811225572, 2022

(CC BY 4.0) | ISSN 2525-3409 | DOI: http://dx.doi.org/10.33448/rsd-v11i2.25572

Figura 6 - Curvas de contorno para a cor instrumental (parâmetros $L^{*}, a^{*}, b^{*} \mathrm{e} \Delta \mathrm{E}$ ) das barras de cereais obtidas pelo Delineamento Composto Central Rotacional

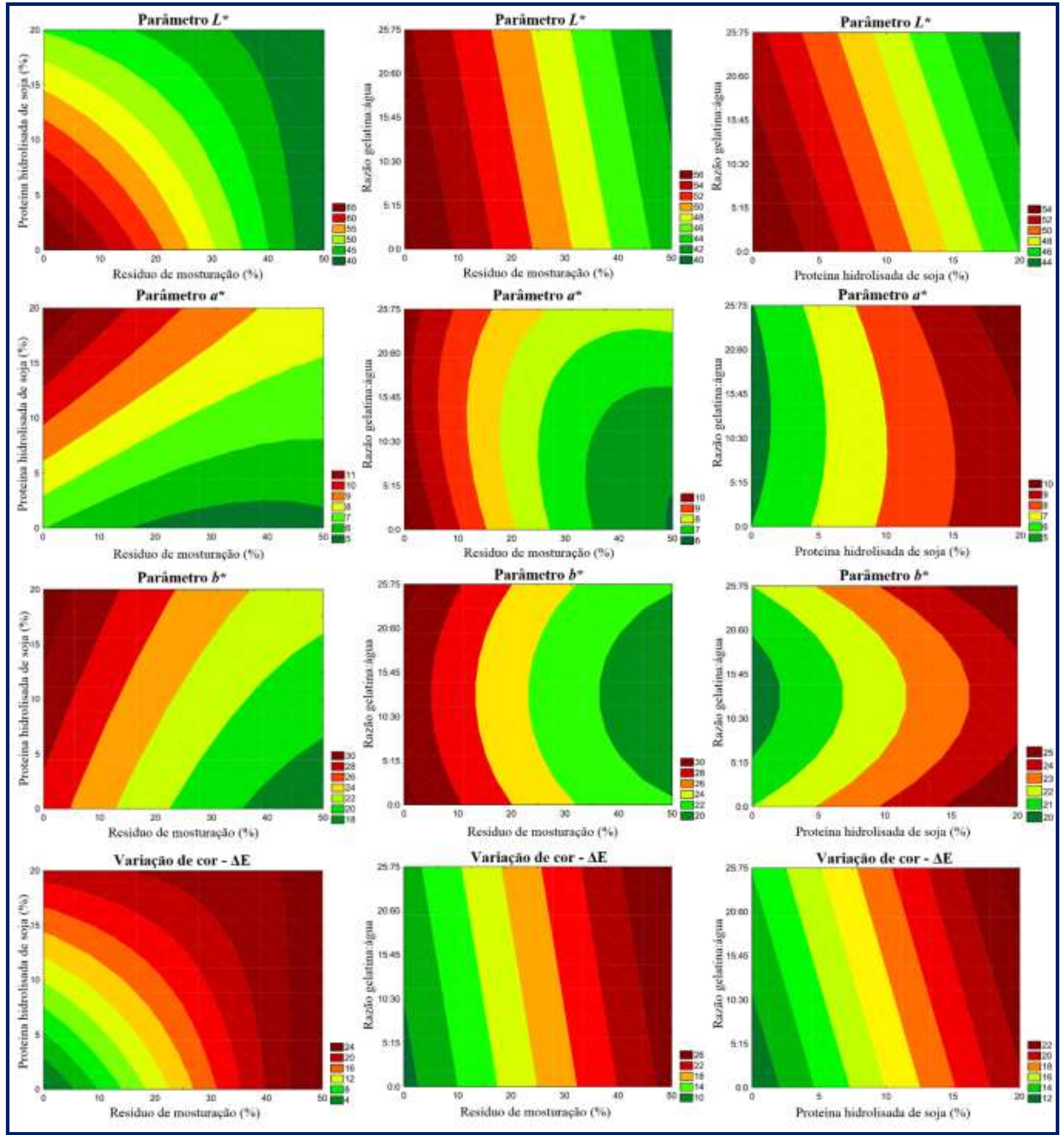

Fonte: Autores (2022). 
Figura 7 - Aparência visual das barras de cereais obtidas pelo Delineamento Composto Central Rotacional

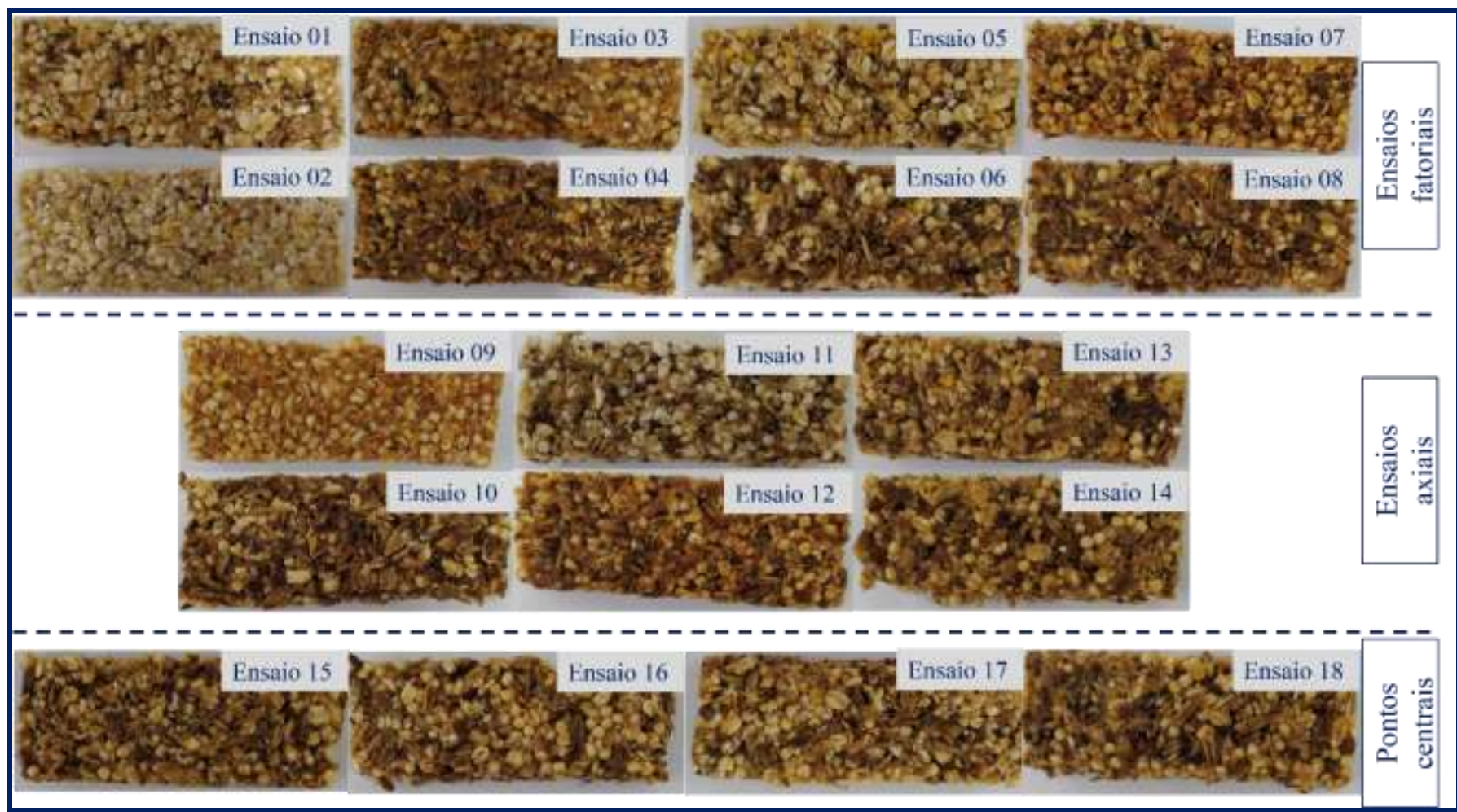

Fonte: Autores (2022).

Os efeitos observados na alteração da coloração das amostras são oriundos das matérias-primas utilizadas neste estudo, ratificados pelos valores da cor instrumental (Tabela 4) e pela aparência visual (Figura 8). Observou-se que o resíduo de mosturação e a proteína hidrolisada de soja apresentaram menores valores de $L^{*}$, quando comparados à mistura de flocos, apresentar. O mesmo comportamento foi observado para a gelatina hidratada, a qual substituiu o xarope de glicose.

Tabela 4 - Cor instrumental das matérias-primas utilizadas como variáveis para a elaboração das barras de cereais de acordo com o Delineamento Composto Central Rotacional

\begin{tabular}{|c|c|c|c|}
\hline \multirow{2}{*}{ Amostra } & \multicolumn{3}{|l|}{ Parâmetro } \\
\hline & $L^{*}$ & $a^{*}$ & $b^{*}$ \\
\hline Mistura de flocos & $75,55 \pm 0,12^{\mathrm{c}}$ & $3,19 \pm 0,14^{\mathrm{c}}$ & $22,19 \pm 0,66^{\mathrm{b}}$ \\
\hline Resíduo de mosturação & $44,85 \pm 0,59^{\mathrm{e}}$ & $5,10 \pm 0,09^{b}$ & $19,55 \pm 0,21^{\mathrm{b}}$ \\
\hline Proteína hidrolisada de soja & $72,86 \pm 0,24^{\mathrm{d}}$ & $9,13 \pm 0,25^{\mathrm{a}}$ & $31,67 \pm 0,68^{a}$ \\
\hline Xarope de glicose & $92,77 \pm 0,20^{\mathrm{a}}$ & $-2,56 \pm 0,02^{\mathrm{e}}$ & $10,47 \pm 0,33^{\mathrm{c}}$ \\
\hline Gelatina & $81,86 \pm 0,51^{\mathrm{b}}$ & $2,12 \pm 0,16^{\mathrm{d}}$ & $20,95 \pm 0,42^{\mathrm{b}}$ \\
\hline p-valor & $<0,001$ & $<0,001$ & $<0,001$ \\
\hline
\end{tabular}

Valores correspondentes à média aritmética de três repetições \pm desvio padrão. Médias com letras distintas na mesma coluna apresentam diferença estatisticamente significativa através do teste Tukey ( $<<0,05)$. Fonte: Autores (2022). 
Figura 8 - Aparência visual das matérias-primas utilizadas como variáveis para a elaboração das barras de cereais de acordo com o Delineamento Composto Central Rotacional

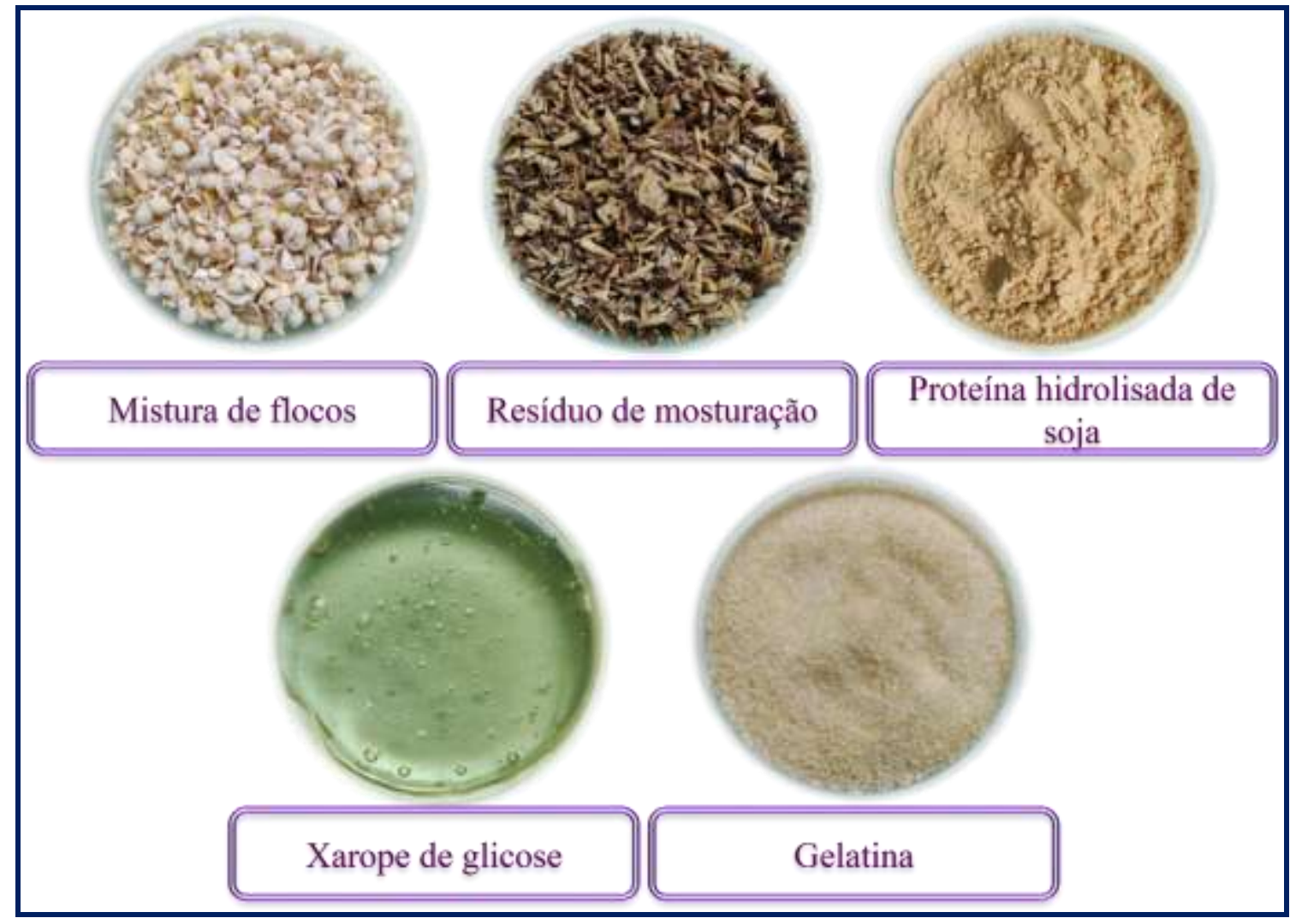

Fonte: Autores (2022).

Em relação ao parâmetro $a^{*}$, maiores diferenças foram observadas em relação aos substitutos parciais da mistura de flocos (resíduo de mosturação e proteína hidrolisada de soja. Em contrapartida, não houve diferença entre a mistura de flocos e o resíduo de mosturação em relação à tonalidade amarelada, os quais também foram semelhantes em relação à gelatina. No entanto, maiores valores de $a^{*}$ foram observados para a proteína hidrolisada de soja.

\subsubsection{Densidade aparente}

$\mathrm{O}$ uso dos ingredientes aglutinantes na elaboração das barras de cereais prove a adequada compactação e viscosidade ao meio para favorecer as características tecnológicas adequadas ao produto. A densidade aparente das barras de cereais elaboradas através do delineamento experimental apresentou valores entre 0,55 e 0,87 mg.mm ${ }^{3}$. Observou-se que a formulação padrão apresentou uma densidade aparente de $0,71 \mathrm{mg} \cdot \mathrm{mm}^{3}$, sendo que o ponto central (ensaios 15-18) apresentaram valores semelhantes (Tabela 2). Os valores experimentais foram explicados em 89,02\% pelo modelo matemático preditivo, com a ANOVA indicando razão de $\mathrm{F}_{\text {cal }} / \mathrm{F}_{\text {tab }(5 ; 12 ; 0,10)}=8,14$ e p-valor $<0,001$. As melhores características tecnológicas para este parâmetro são obtidas com maiores valores de densidade aparente. Desta forma, o termo linear da proteína hidrolisada de soja $\left(\beta_{2}=0,05 ; \mathrm{p}=0,003\right)$ apresentou o melhor efeito. Como alguns valores dos ensaios foram obtidos acima da amostra padrão, o uso do resíduo de mosturação $\left(\beta_{1}=-0,08 ; \mathrm{p}<0,001\right)$ apresentou potencial de aplicação (Tabela 3$)$, uma vez que atenua a compactação excessiva do produto, a ponto de deixá-lo coeso demais para a mastigabilidade no momento do consumo. Ao avaliar as curvas de contorno (Figura 9), observamos que as barras de cereais com maior compactação foram obtidas com menores teores de resíduo de mosturação, maiores níveis de proteína hidrolisada de soja e 
quantidades intermediárias de gelatina hidratada. As maiores compactações podem ser resultado do melhor preenchimento da estrutura porosa por parte dos agentes ligantes e da melhor dispersão dos constituintes que formam a barra de cereal (Martins et al., 2021).

\subsubsection{Textura instrumental}

A amostra padrão elaborada apresentou uma fraturabilidade de $100,99 \mathrm{~N}$, sendo que os ensaios apresentaram forças de primeira ruptura entre 18,16 e 174,60 N (Tabela 2). Observou-se que 82,68 \% dos valores experimentais foram explicados pelo modelo matemáticos, segundo a ANOVA $\left(\mathrm{F}_{\mathrm{cal}} / \mathrm{F}_{\mathrm{tab}(8 ; 9 ; 0,10)}=2,09\right.$ e p-valor < 0,001). O termo quadrático da razão gelatina:água $\left(\beta_{33}=33,24 ; \mathrm{p}<0,001\right)$ resultou em redução nos valores de fraturabilidade, enquanto o termo linear $\left(\beta_{1}=-23,08 ; \mathrm{p}=0,011\right)$ desta mesma variável promoveu maiores valores (Tabela 3). As curvas de contorno (Figura 9) indicam que as maiores fraturabilidades foram obtidas com uso de resíduo de mosturação $<25 \%$, de proteína hidrolisada de soja > $10 \%$ e aplicação de gelatina hidratada entre 10-20\%. Estes resultados indicam que o uso combinado entre o resíduo de mosturação e a proteína hidrolisada de soja tendem a reestabelecer a força de fratura das barras elaboradas neste experimento. Em contrapartida, baixos teores de gelatina hidratada não apresentaram força (coesão) o suficiente para manter a integridade estrutural das barras e o excesso da proteína animal resultou em texturas gomosas, as quais podem apresentar dificuldade para a mastigação (Melati, Lucchetta, Prado, Oliveira, \& Tonial, 2021). Além disso, a migração da água adicionada à formulação para a hidratação da gelatina tende a migrar por difusão para os carboidratos, favorecendo a maleabilidade e o estado gomoso das fibras alimentares, aumentando a força necessária para a deformação do produto (Srebernich, Gonçalves, Ormenese, \& Ruffi, 2016).

A propriedade de compactação das barras de cereais favorecida pelo uso do hidrolisado proteico de soja pode ser observada nos dados de força de cisalhamento, os quais variaram entre 132 e $323 \mathrm{~N}$ para os 18 ensaios do delineamento experimental (Tabela 2). A ANOVA apresentou razão $F_{\text {cal }} / F_{\text {tab }(9 ; 8 ; 0,10)}=0,58$, p-valor $=0,321$ e $R^{2}=61,26 \%$, indicando que o modelo matemático não foi possível de explicar a quantidade mínima dos resultados experimentais. No entanto, observou-se que o termo linear da proteína hidrolisada de soja $\left(\beta_{2}=40,06 ; \mathrm{p}<0,001\right)$ e a interação entre o resíduo de mosturação com a proteína hidrolisada de soja $\left(\beta_{12}=25,69 ; \mathrm{p}=0,006\right)$ resultaram em maiores forças de cisalhamento. A amostra padrão apresentou $323 \mathrm{~N}$ de força de cisalhamento (Tabela 2) e, quando compararmos os valores deste ensaio com os demais, observamos que o termo linear do resíduo de mosturação $\left(\beta_{1}=-28,75 ; \mathrm{p}=0,002\right)$ (Tabela 3$)$ amenizou a força necessária para o corte das barras, o que foi proporcionado pela menor compactação promovida pelas fibras alimentares, corroborando com os resultados obtidos para a densidade aparente das barras de cereais.

Baqeri, Nejatian, Abbaszadeh, \& Taghdir (2020) elaboraram uma barra comestível (snack bar) a base pasta de gergelim e calda de tâmara, utilizando a gelatina como agente ligante. Os autores observaram que a concentração de 0,7 \% de gelatina foi o suficiente para atingir a ação necessária na formação da estrutura das barras, favorecendo a dureza, a coesividade, a mastigabilidade e a transparência do produto. A interação entre os carboidratos (quando presentes em maiores concentrações) e as proteínas apresentam uma incompatibilidade termodinâmica de mistura por conta do efeito de exclusão de volume em virtude do tamanho das moléculas, proporcionando a separação de fases, pelo desfavorecimento da isotropia em função da heterogeneidade das fases, envolvendo principalmente a sacarose, a glicose e a frutose na presença de proteína com boas propriedades hidrodinâmicas, como a gelatina e a proteína da soja. A concentração limite para favorecer a interação carboidrato-proteína é de no mínimo $4 \%$, resultando na formação de agregados que proporcionem maior rigidez ao meio (Damodaran \& Parkin, 2017). Altos valores de dureza, fraturabilidade, coesão, mastigabilidade e força de cisalhamento não são desejados em barras de cereais, sendo que estas características são proporcionadas por concentrações elevadas de agentes ligantes (Sethupathy, Suriyamoorthy, Moses, \& Chinnaswamy, 2020). De acordo com Melati et al. (2021), Samakradhamrongthai, Jannu, \& Renaldi (2021), o uso de colágeno como agente ligante resultam em texturas com menores 
durezas e com menor resistência ao corte quando comparadas aos carboidratos como xantana e goma guar. As barras de cereais com menores dureza e fraturabilidade são mais fáceis de serem mastigadas. Isso significa que o alimento não necessita de muito tempo para se desintegrar durante a mastigação, característica essencial para que as barras de cereais sejam sensorialmente aceitas, como uma textura íntegra e rígida, mas quebrável quando comprimido entre os dentes.

\subsubsection{Atividade de água e umidade}

A atividade de água para as amostras apresentou níveis inferiores de 0,6614 e superiores de 0,9718, sendo que a amostra padrão apresentou atividade de água de 0,6245 (Figura 5). O termo linear da razão gelatina:água apresentou o maior efeito em aumentar a atividade de água do produto $\left(\beta_{3}=0,0927 ; \mathrm{p}<0,001\right)$. O gel formado com a geleificação da gelatina é capaz de aprisionar grande quantidade de água, mas esta fase líquida fica disponível para reações química, bioquímicas e microbiológicas. A combinação entre o resíduo de mosturação e a gelatina hidratada favoreceu levemente a redução da atividade de água $\left(\beta_{13}=-0,0073 ; \mathrm{p}=0,048\right)$ (Tabela 3). Os resultados experimentais foram explicados em 99,00\% pelo modelo matemático preditivo da ANOVA $\left(\mathrm{F}_{\mathrm{cal}} / \mathrm{F}_{\mathrm{tab}}(3 ; 14 ; 0,10)=183,60\right.$, $\mathrm{p}$-valor $\left.<0,001\right)$. De acordo com o observado na curva de contorno (Figura 9), menores níveis de resíduo de mosturação e de gelatina hidratada favorecem as menores atividades de água, favorecendo assim a vida de prateleira das barras de cereais, principalmente em relação a estabilidade microbiológica. Aumento na atividade de água também foram observados por Samakradhmrongthai et al. (2021), Pallavi, Chetana, Ravi, \& Reddy (2015) e Martins et al. (2021) ao utilizarem agentes ligantes não convencionais (sorbitol, manitol, maltitol, maltodextrinas, goma lacuste, carboximetilcelulose, pectina e mel) em barras de cereais.

Comportamento diretamente proporcional foi observado entre a atividade de água e a umidade das barras de cereais, para a qual o termo linear da razão gelatina:água apresentou o maior efeito em aumentar a umidade dos ensaios $\left(\beta_{3}=8,82\right.$; $\mathrm{p}<0,001)$ e a interação entre o resíduo de mosturação e a razão gelatina:água $\left(\beta_{13}=-0,61 ; \mathrm{p}=0,090\right)$ reduziu o teor de umidade das amostras (Tabela 3). O uso da proteína hidrolisada de soja não apresentou efeito sobre a variável em estudo. A ANOVA apresentou valores de $\mathrm{R}^{2}$ de $98,85 \%$, razão $\mathrm{F}_{\text {cal }} / \mathrm{F}_{\text {tab }(4 ; 13 ; 0,10)}=115,36$, p-valor $<0,001$, inferindo a predição dos modelos matemáticos. A umidade dos ensaios foi maior (9,63 a 36,92 \%) quando comparada a amostra padrão $(8,44 \%) \mathrm{em}$ função do uso da gelatina hidratada (Figura 5). No entanto Maia et al. (2021) obtiveram valores de umidade (9,30-10,32\%) e atividade de água $(0,523-0,557)$ próximas ao encontrado no presente estudo ao aplicarem proteínas de leguminosas (ervilha, feijão caupi e feijão mangalô). Da mesma forma, Borges et al. (2021) encontraram valores de umidade entre 11-12\% e atividade de água entre 0,554 e 0,571 para barras de cereais enriquecidas com biomassa de fermentação de vinho. A curva de contorno (Figura 9) indicou que menores valores de umidade foram obtidos com os menores níveis de resíduo de mosturação e da razão gelatina:água. O resíduo de mosturação é composto por fibras alimentares solúveis e insolúveis, sendo esta última fração a predominante na cevada. As fibras insolúveis possuem grande capacidade de hidratação e de retenção de água, onde parte da água fica somente adsorvida na matriz dos polissacarídeos não amiláceos, mas parte da água poder formar ligações de hidrogênio dos grupamentos funcionais $(\mathrm{OH})$ com a água, reduzindo assim a quantidade de água livre (Martins et al., 2021; Pathania \& Kaur, 2022; Xiong et al., 2022) sugerem que a secagem forçada apresenta potencial para favorecer a umidade e a atividade de água adequada para barras de cereais com substitutos de agentes aglutinantes tradicionais. Além disso, os autores testaram temperaturas de secagem de 20,60 e $70{ }^{\circ} \mathrm{C}$, sendo que a maior temperatura de secagem favoreceu atributos como a textura instrumental. 
Figura 9 - Curvas de contorno para a densidade aparente, fraturabilidade, atividade de água e umidade das barras de cereais obtidas pelo Delineamento Composto Central Rotacional

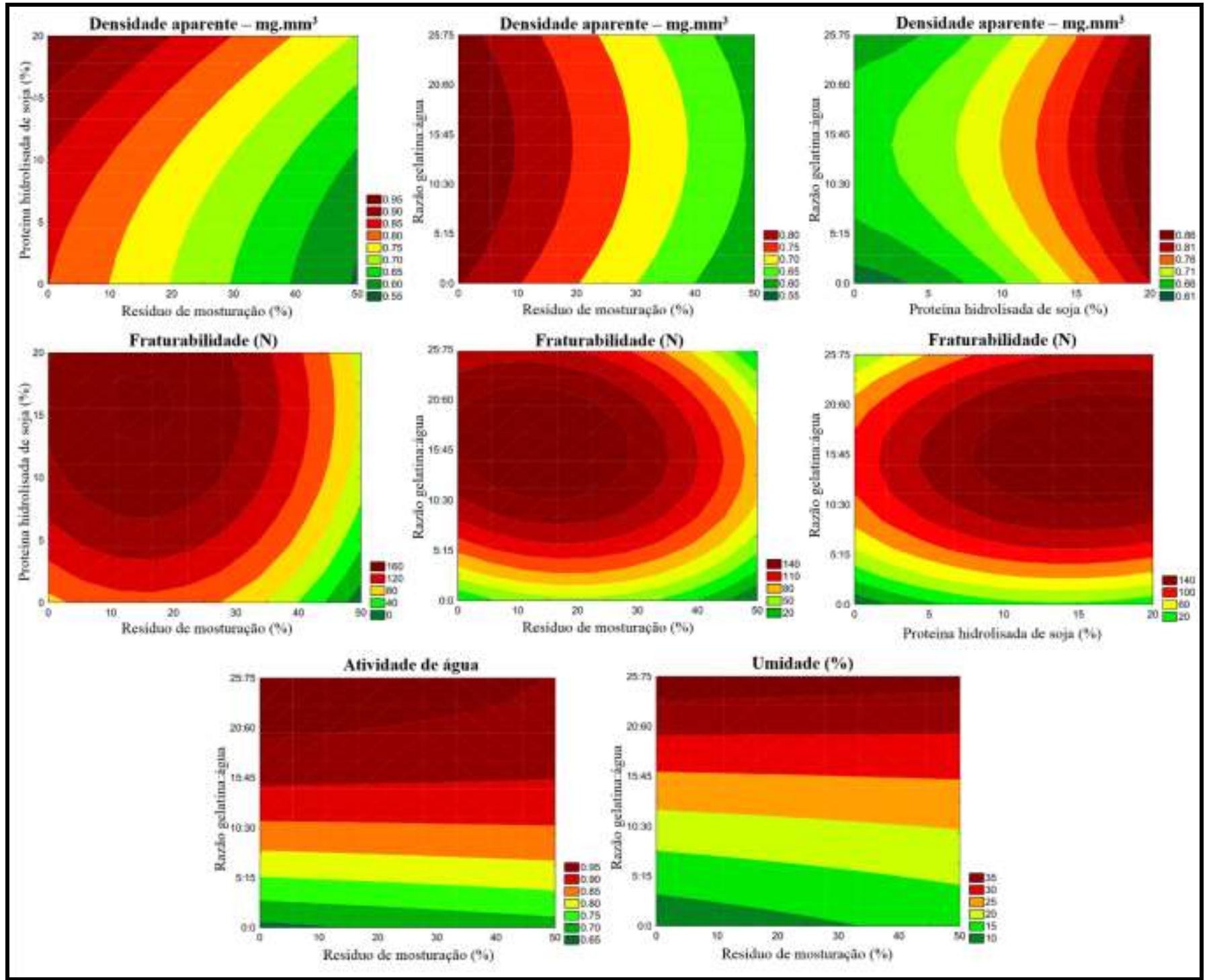

Fonte: Autores (2022).

\subsection{Otimização numérica e validação dos modelos matemáticos}

A otimização da formulação adequada foi realizada em relação as características tecnológicas das barras de cereais, de forma que se obtivesse um teor mínimo de $12 \%$ de proteína hidrolisada de soja incorporada, visto que esta variável dependente apresentou os melhores resultados no produto final e o complemento no perfil de aminoácidos essenciais. Os níveis de resíduo de mosturação e gelatina hidratada foram otimizados dentro da faixa estudada. Para as variáveis dependentes estatisticamente significativas $\left(\mathrm{p}<0,10 ; \mathrm{F}_{\mathrm{cal}} / \mathrm{F}_{\mathrm{tab}}>1\right.$ e $\left.\mathrm{R}^{2}>0,80\right)$ foram atribuídas importâncias entre 1 e 5 , sendo 1 considerada uma importância menor e 5 uma importância maior. O alvo foi definido como "maximizar" (a variação de cor instrumental e a densidade aparente), "na faixa" (parâmetros $a^{*}$ e $b^{*}$ e a fraturabilidade) e "minimizar" (o parâmetro $L^{*}$, a atividade de água e a umidade) (Tabela 5).

A melhor solução obtida com o uso de $27,08 \%$ de resíduo de mosturação, 12,44 \% de proteína hidrolisada de soja e 0,89 \% de gelatina com 2,67 \% de água. Esta formulação foi processada em triplicata verdadeira e as variáveis dependentes foram analisadas para verificar a validade dos modelos matemáticos. Nas condições estipuladas, foi estabelecido um grau de 
desejabilidade de 75,03\%. De maneira geral, observou-se que modelos matemáticos predizem os valores experimentais e podem ser considerados válidos, uma vez que o desvio relativo encontrado foi de até $\pm 10 \%$.

Tabela 5 - Otimização numérica, valores preditos e experimentais para a validação dos modelos matemáticos

\begin{tabular}{|c|c|c|c|c|c|}
\hline \multirow{2}{*}{ Parâmetro } & \multirow{2}{*}{ Alvo } & \multirow{2}{*}{ Importância } & \multicolumn{3}{|l|}{ Solução } \\
\hline & & & \multicolumn{2}{|c|}{ Valores codificados } & Valores reais \\
\hline \multicolumn{6}{|l|}{ Variáveis independentes } \\
\hline Resíduo de mosturação & $\mathrm{Na}$ faixa & 4 & $+0,14$ & & $27,08 \%$ \\
\hline Proteína hidrolisada de soja & Meta $=0,34$ & 5 & $+0,41$ & & $12,44 \%$ \\
\hline Razão gelatina:água & Na faixa & 5 & $-1,65$ & & $0,89: 2,67 \%$ \\
\hline Parâmetro & Alvo & Importância & Solução & Valor experimental & Desvio relativo \\
\hline \multicolumn{6}{|l|}{ Variáveis dependentes } \\
\hline$L^{*}$ & Minimizar & 5 & 48,29 & $49,44 \pm 0,78$ & $+2,38 \%$ \\
\hline$a^{*}$ & $\mathrm{Na}$ faixa & 3 & 7,43 & $7,76 \pm 0,22$ & $+4,38 \%$ \\
\hline$b^{*}$ & $\mathrm{Na}$ faixa & 3 & 23,20 & $23,60 \pm 0,46$ & $+1,72 \%$ \\
\hline Variação de cor & Maximizar & 3 & 17,44 & $15,94 \pm 0,80$ & $-8,63 \%$ \\
\hline Densidade aparente $\left(\mathrm{mg} \cdot \mathrm{mm}^{-3}\right)$ & Maximizar & 5 & 0,69 & $0,67 \pm 0,02$ & $-2,47 \%$ \\
\hline Fraturabilidade $(\mathrm{N})$ & $\mathrm{Na}$ faixa & 3 & 28,16 & $30,59 \pm 1,04$ & $+8,64 \%$ \\
\hline Atividade de água & Minimizar & 5 & 0,6644 & $0,6624 \pm 0,0043$ & $-0,29 \%$ \\
\hline Umidade $(\%)$ & Minimizar & 5 & 9,52 & $10,28 \pm 0,16$ & $+8,02 \%$ \\
\hline Desejabilidade & 0,7503 & & & & \\
\hline
\end{tabular}

Fonte: Autores (2022).

Para um melhor entendimento dos resultados, duas amostras comerciais com características visuais próximas à barra de cereal padrão elaborada neste estudo foram adquiridas em comércio local e avaliadas quanto à densidade aparente, a textura instrumental (fraturabilidade e força de cisalhamento), a atividade de água e a umidade (Tabela 6). Observou-se que as amostras apresentaram valores próximos de densidade aparente, atividade de água e umidade. Os maiores valores de fraturabilidade e força de cisalhamento podem estar atribuídos pelas dimensões das barras, sendo que as barras comerciais apresentaram uma largura de $17 \%$ maior em relação a amostra padrão elaborada neste estudo. De modo geral, entendemos que nossas amostras apresentaram características tecnológicas satisfatórias quando comparadas a amostra padrão e as marcas comerciais. 
Tabela 6 - Parâmetros de densidade aparente, fraturabilidade, força de cisalhamento, atividade de água, umidade valor calórico total e aparência visual de duas amostras comerciais de barras de cereais semelhantes à barra de cereal padrão elaborada neste estudo.

\begin{tabular}{lll}
\hline Parâmetro & Barra de cereal com banana & Barra de cereal com castanha \\
\hline Densidade aparente $\left(\mathrm{mg} \cdot \mathrm{mm}^{-3}\right)(\mathrm{n}=3)$ & $0,72 \pm 0,06$ & $0,70 \pm 0,05$ \\
Fraturabilidade $(\mathrm{N})(\mathrm{n}=6)$ & $41,77 \pm 4,25$ & $37,50 \pm 7,82$ \\
Força de cisalhamento $(\mathrm{N})(\mathrm{n}=10)$ & $199 \pm 14$ & $180 \pm 29$ \\
Atividade de água $(\mathrm{n}=3)$ & $0,5854 \pm 0,0004$ & $0,6023 \pm 0,0016$ \\
Umidade (\%) $(\mathrm{n}=3)$ & $5,04 \pm 0,01$ & $5,06 \pm 0,02$ \\
Valor energético total & 112 & 119 \\
(kcal por porção)* & &
\end{tabular}

Aparência visual
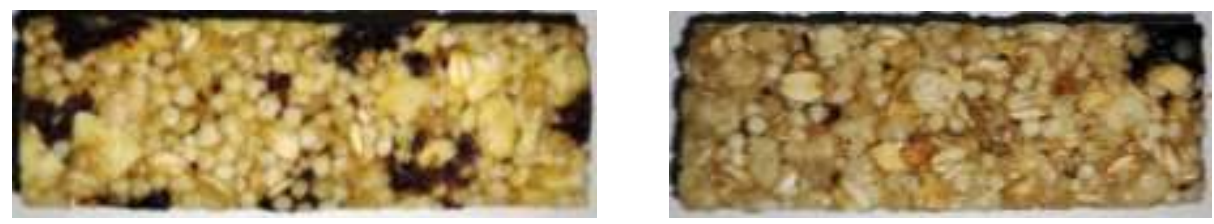

Valores correspondentes a média aritmética \pm desvio padrão. *Valor estabelecido no rótulo do produto. Fonte: Autores (2022).

\subsection{Composição centesimal e valor calórico total}

Os valores de composição centesimal e valor calórico total da amostra padrão e do ponto otimizado estão apresentados na Tabela 7 e a aparência visual pode ser observada na Figura 10. Observou-se que todos os parâmetros foram influenciados estatisticamente $(\mathrm{p} \leq 0,001)$, sendo que o ponto otimizado apresentou maiores teores de umidade, cinzas, proteínas e fibra alimentar total em relação a amostra padrão. Os maiores aumentos foram de proteínas (126,83 \%) e de fibra alimentar total $(85,62 \%)$. Estes resultados são explicados pelo teor proteico de 60-61 \% da proteína hidrolisada de soja (Schmiele et al., 2017a) e aproximadamente 40 \% (em base seca) fibras alimentares no resíduo de mosturação de cerveja após o processo de secagem (Shih et al., 2020). Em contrapartida, houve redução nos teores de lipídeos, açúcares totais e amido, sendo três componentes altamente calóricos. A redução nos teores de açúcares e amido inferem que o ponto otimizado apresenta menor índice glicêmico em relação à amostra controle. Por outro lado, o aumento do teor de proteínas e a mistura entre proteínas de origem vegetal (cereais e leguminosas) e animal, provavelmente resultaram em um melhor balanço de aminoácidos essenciais, além do aumento do teor de nitrogênio proteico.

Considerando que uma porção de barra de cereais corresponde a 1 unidade de $30 \mathrm{~g}$ de acordo com a Resolução Diretoria Colegiada - RDC no 259, de 23 de dezembro de 2003 (Brasil, 2003), houve uma redução de 19,27 \% no valor calórico total da formulação otimizada $(88,69 \mathrm{kcal}$ por porção). Além disso, as barras desenvolvidas neste estudo apresentaram valor calórico total menor que as barras comerciais utilizadas para padrões de referência (Tabela 6). De acordo com a RDC $\mathrm{n}^{\circ}$ 54, de 12 de novembro de 2012 (Brasil, 2012), a porção de barras de cereais apresentou baixo teor de gorduras totais e alto conteúdo de fibra alimentar total. Quando comparada à amostra padrão, a barra de cereal do ponto otimizado apresentou aumentado os teores de proteínas, minerais e fibras alimentares. As farinhas de leguminosas ou a aplicação de farinhas não convencionais promovem melhora no perfil nutricional dos alimentos, principalmente em relação ao teor de proteínas, minerais e fibras alimentares (Maia et al., 2021; Moreira-Araújo, Sousa, Cavalcante, Morgano, \& Araújo, 2021). 
Tabela 7 - Composição centesimal e valor calórico total das barras de cereais referentes à amostra padrão e ao ponto otimizado

\begin{tabular}{llccc}
\hline Amostra & Padrão & Ponto ótimo & p-valor & Diferença do componente (\%) \\
\hline Umidade (\%) & $8,44 \pm 0,11$ & $10,28 \pm 0,16$ & $<0,001$ & $+21,77$ \\
Lipídeos (\%) & $5,54 \pm 0,07$ & $4,61 \pm 0,06$ & $<0,001$ & $-16,81$ \\
Cinzas (\%) & $1,32 \pm 0,01$ & $1,55 \pm 0,03$ & $<0,001$ & $+17,25$ \\
Proteínas (\%) & $3,77 \pm 0,02$ & $8,54 \pm 0,04$ & $<0,001$ & $+126,83$ \\
Açúcares totais $(\%$, em glicose) & $29,92 \pm 0,12$ & $25,32 \pm 1,32$ & 0,001 & $-15,38$ \\
Amido (\%) & $36,26 \pm 1,11$ & $22,30 \pm 0,95$ & $<0,001$ & $-38,50$ \\
Fibra alimentar total (\%) & $14,76 \pm 1,12$ & $27,41 \pm 1,66$ & $<0,001$ & $+85,62$ \\
\hline Valor calórico total (kcal por porção*) & 109,86 & 88,69 & - & $-19,27$ \\
\hline
\end{tabular}

Valores correspondentes a média aritmética de três repetições \pm desvio padrão para a composição centesimal. *De acordo com a Resolução Diretoria Colegiada $n^{\circ} 259$, de 23 de dezembro de 2003, uma porção de barra de cereais com teor de lipídeos inferior a $10 \%$ corresponde a $30 \mathrm{~g}$ (Brasil, 2003). Fonte: Autores (2022).

Figura 10 - Aparência visual das barras de cereais referente à amostra padrão e o ponto otimizado com o uso do resíduo de mosturação, proteína hidrolisada de soja e da razão gelatina:água

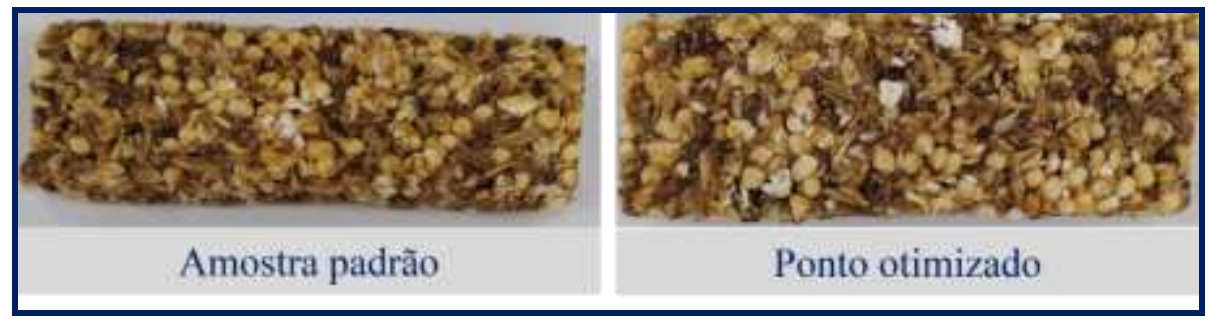

Fonte: Autores (2022).

\section{Conclusão}

Observou-se que a temperatura de $80{ }^{\circ} \mathrm{C}$ foi a mais adequada para o processo de secagem do resíduo de mosturação da cerveja. O processo de otimização estatística permitiu substituir parcialmente a mistura de flocos $(39,52 \%)$ pelo resíduo de mosturação $(27,08 \%)$ e pela proteína hidrolisada de soja $(12,44 \%)$. No entanto, a substituição do xarope de glicose foi relativamente baixa, o que se deu pela grande quantidade de água utilizada no processo de hidratação da gelatina, resultando em aumento significativo da umidade e da atividade de água das barras de cereais, comprometendo a estabilidade e segurança microbiológica do produto. O ponto otimizado permitiu a elaboração de barras de cereais com aumentos significativos nos teores de proteínas, fibras alimentes e minerais, além de favorecer a redução no conteúdo de lipídeos, açúcares e amido e no valor calórico do produto. A viabilidade do uso de matérias-primas não convencionais para melhorar nutricionalmente as barras de cereais, sem alterações drásticas em relação às propriedades tecnológicas, ficou evidenciada neste trabalho. Sugere-se que uma avaliação sensorial poderia definir a percepção do consumidor em relação ao produto desenvolvido. Esta etapa não foi realizada em função das restrições impostas pela pandemia do coronavírus respiratório, o Sars-CoV-2. Além disso, os 
pesquisadores envolvidos no trabalho em laboratório sugerem que as barras poderiam ser recobertas com um topping de frutas utilizando-se hidrocoloides para fornecer a estruturação adequada do gel, para que não haja aumento significativo no valor calórico das barras de cereais. Considerando os teores de fibras alimentares e de proteínas, acreditamos que os sabores de pêssego e baunilha poderão ser promissores.

\section{Agradecimentos}

Os autores agradecem à Universidade Federal dos Vales do Jequitinhonha e Mucuri (UFVJM) e ao Instituto de Ciência e Tecnologia (ICT) pelo suporte institucional. Agradecemos ao Conselho Nacional de Desenvolvimento Científico e Tecnológico $(\mathrm{CNPq})$ e à Coordenação de Aperfeiçoamento de Pessoal de Nível Superior pelo suporte financeiro, protocolo 424938/2016-2 e código de financiamento 001, respectivamente. Por fím, ficamos gratos à Cervejaria Diamantina (Diamantina, MG) pela doação do resíduo de mosturação e à HT Nutri (Camaquã, RS) por fornecer a proteína hidrolisada de soja.

\section{Referências}

AACCI. (2010). American Association of Cereal Chemists International. Approved Methods of American Association of Cereal Chemists. AACC, St. Paul.

André, A. M. M. C. N., Nascimento, A. P. S., Almeida, R. L. J., Santos, N. C., \& Almeida, R. D. (2018). Modelagem matemática para descrição da cinetica de secagem das semente de maracujá amarelo. In Congresso Técnico Científico da Engenharia e da Agronomia CONTECC'.

Antunes, K. H., Fachi, J. L., Paula, R., Silva, E. F., Pral, L. P., Santos, A. Á., ... Souza, A. P. D. (2019). Microbiota-derived acetate protects against respiratory syncytial virus infection through a GPR43-type 1 interferon response. Nature Communications, 10(1), 3273. https://doi.org/10.1038/s41467-019-11152-6

AOAC. (2019). Official Methods of Analysis of AOAC International. 21 a ed. Association of Official Analysis Chemists International, Gaithersburg.

Ashraf, A., Ramamurthy, R., \& Rene, E. R. (2021). Wastewater treatment and resource recovery technologies in the brewery industry: Current trends and emerging practices. Sustainable Energy Technologies and Assessments, 47, 101432. https://doi.org/10.1016/j.seta.2021.101432

Baqeri, F., Nejatian, M., Abbaszadeh, S., \& Taghdir, M. (2020). The effect of gelatin and thymol-loaded nanostructured lipid carrier on physicochemical, rheological, and sensory properties of sesame paste/date syrup blends as a snack bar. Journal of Texture Studies, 51(3), 501-510. https://doi.org/10.1111/jtxs.12511

Barbosa, E. S. P., \& Coelho, N. R. A. (2008). Elaboração e avaliação sensorial de barra de cereais de linhaça. Revista Processos Químicos, 2 (4), 62-67. https://doi.org/10.19142/rpq.v2i4.69

Bernaud, F. S. R., \& Rodrigues, T. C. (2013). Fibra alimentar: ingestão adequada e efeitos sobre a saúde do metabolismo. Arquivos Brasileiros de Endocrinologia \& Metabologia, 57(6), 397-405. https://doi.org/10.1590/S0004-27302013000600001

Bessada, S. M. F., Barreira, J. C. M., \& Oliveira, M. B. P. P. (2019). Pulses and food security: Dietary protein, digestibility, bioactive and functional properties. Trends in Food Science \& Technology, 93, 53-68. https://doi.org/10.1016/j.tifs.2019.08.022

Borges, I. M. S., Almeida, R. L. J., Fernandes, A. C. G., Silva, S. É., Silva, M. L. A., Barros, U. I. G., ... Freire, J. G. T. B. (2020). Agricultura familiar: análise de sustentabilidade através de indicadores sociais econômicos e ambientais. Research, Society and Development, 9(4), e54942832. https://doi.org/10.33448/rsd-v9i4.2832

Borges, M. S., Biz, A. P., Bertolo, A. P., Bagatini, L., Rigo, E., \& Cavalheiro, D. (2021). Enriched cereal bars with wine fermentation biomass. Journal of the Science of Food and Agriculture, 101(2), 542-547. https://doi.org/10.1002/jsfa.10664

Brasil. (2003). Ministério da Saúde. Agência Nacional de Vigilância Sanitária. Lei no 10.674, de 16 de maio de 2003. Obriga que os produtos alimentícios comercializados informem sobre a presença de glúten, como medida preventiva e de controle da doença celíaca. Diário Oficial da União, Poder Executivo, Brasília, DF, 19 de maio de 2003. Seção 1, página 1.

Brasil. (2005) Ministério da Saúde. Agência Nacional de Vigilância Sanitária. Resolução RDC nº 263 de 22 de setembro de 2005 . Regulamento técnico para produtos de cereais, amidos, farinhas e farelos. Diário Oficial da União, Poder Executivo, Brasília, DF.

Brasil. (2012). Ministério da Saúde. Agência Nacional de Vigilância Sanitária. Resolução RDC no 54 de 12 de novembro de 2012 . Dispõe sobre o regulamento técnico sobre informação nutricional complementar. Diário Oficial da União, Poder Executivo, Brasília, DF.

Carneiro, H. L., Queiroz, V. A. V., Porto, F. L., \& Queiroz, M. V. R. (2018). Elaboração e a avaliação sensorial de uma barra de cereais a base de pipoca de sorgo (Sorghum bicolor L.). Revista Científica Intelletto, 3(2), 13-20.

Carvalho, H. J. M., Santos, M. P., Silva, M. B., Silveira, J. V. W., \& Schmiele, M. (2020). Performace de coprodutos da cervejaria artesanal nas propriedades tecnológicas de bolo inglês. In $1^{\circ}$ Simpósio Nacional sobre Inovação em Engenharia e Ciência de Alimentos - INECA2020. 
Castañeda-Pérez, E., Jiménez-Morales, K., Castellanos-Ruelas, A., Chel-Guerrero, L., \& Betancur-Ancona, D. (2021). Antidiabetic potential of protein hydrolysates and peptide fractions from lima bean (Phaseolus lunatus L.): An in vitro study. International Journal of Peptide Research and Therapeutics, 27(3), 1979-1988. https://doi.org/10.1007/s10989-021-10226-8

Damodaran, S., \& Parking, K. L. (2017). Fennema's Food Chemistry, Fifth Edition. CRC Press. https://doi.org/10.1201/9781315372914

Das, B., \& Das, S. K. (2021). Advances in Drying Technology for Food Processing. In Food Processing (p. 25-43). CRC Press. https://doi.org/10.1201/9780429321481

Derringer, G., \& Suich, R. (1980). Simultaneous optimization of several response variables. Journal of Quality Technology, 12(4), 214-219. https://doi.org/10.1080/00224065.1980.11980968

Dia, V. P., Gomez, T., Vernaza, G., Berhow, M., Chang, Y. K., \& Mejia, E. G. (2012). Bowman-Birk and Kunitz protease inhibitors among antinutrients and bioactives modified by germination and hydrolysis in Brazilian soybean cultivar BRS 133. Journal of Agricultural and Food Chemistry, 60(32), 7886-7894. https://doi.org/10.1021/jf301926w

Ferreira, A. R., Gianasi, F., Moro, T. M. A., Felisberto, M. H. F., Neves, E. C. A., \& Clerici, M. T. P. S. (2021). Functional Pasta: A Comparative Study of the Use of Bamboo Fibers and White Fibers. In Biotechnological Advances in Bamboo (p. 431-446). Singapore: Springer Singapore. https://doi.org/10.1007/978981-16-1310-4_18

Furlan, L. S., \& Boldrini, M. G. (2013). Dossiê gelificantes. Revista food Ingredients, 27, 42-49.

Gibelato, G. F. B., Oliveira, W. S., Neves, E. C. A., Godoy, H. T., Chang, Y. K., \& Schmiele, M. (2016). Cereal matinal glúten-free a base de farinhas de sorgo, arroz e chia. In XXV Congresso Brasileiro de Ciência e Tecnologia de Alimentos.

González-Montoya, M., Hernández-Ledesma, B., Silván, J. M., Mora-Escobedo, R., \& Martínez-Villaluenga, C. (2018). Peptides derived from in vitro gastrointestinal digestion of germinated soybean proteins inhibit human colon cancer cells proliferation and inflammation. Food Chemistry, 242, 75-82. https://doi.org/10.1016/j.foodchem.2017.09.035

Goula, A. M., Chasekioglou, A. N., \& Lazarides, H. N. (2015). Drying and shrinkage kinetics of solid waste of olive oil processing. Drying Technology, 33(14), 1728-1738. https://doi.org/10.1080/07373937.2015.1026983

He, Y., Guo, J., Ren, G., Cui, G., Han, S., \& Liu, J. (2020). Effects of konjac glucomannan on the water distribution of frozen dough and corresponding steamed bread quality. Food Chemistry, 330, 127243. https://doi.org/10.1016/j.foodchem.2020.127243

Hughes, J., \& Grafenauer, S. (2021). Oat and barley in the food supply and use of beta glucan health claims. Nutrients, 13(8), 2556. https://doi.org/10.3390/nu13082556

Jiang, Z., Wang, K., Zhao, X., Li, J., Yu, R., Fu, R., ... Hou, J. (2021). High-protein nutrition bars: Hardening mechanisms and anti-hardening methods during storage. Food Control, 127, 108127. https://doi.org/10.1016/j.foodcont.2021.108127

Jones, J. M., García, C. G., \& Braun, H. J. (2020). Perspective: Whole and refined grains and health - Evidence supporting "Make half your grains whole". Advances in Nutrition, 11(3), 492-506. https://doi.org/10.1093/advances/nmz114

Lasta, E. L., Ronning, E. S. P., Dekker, R. F. H., \& Cunha, M. A. A. (2021). Encapsulation and dispersion of Lactobacillus acidophilus in a chocolate coating as a strategy for maintaining cell viability in cereal bars. Scientific Reports, 11(1), 20550. https://doi.org/10.1038/s41598-021-00077-0

Maia, L. C., Nano, R. M. W., Santos, W. P. C., Oliveira, F. S., Barros, C. O., \& Miranda, K. E. S. (2021). Evaluation of the nutritional quality of cereal bars made with pulse flours using desirability functions. Food Science and Technology International, 27(8), 702-711. https://doi.org/10.1177/1082013220983080

Martins, V., Alves, M. R., \& Pinheiro, R. (2021). Analysis of microstructure and texture of gluten- and lactose-free cereal bars, produced with different hydrocolloids and drying temperatures and no-added sugar. Journal of Food Processing and Preservation, 45(4), e15238. https://doi.org/10.1111/jfpp.15238

Mastelini, S. M., Sasso, M. G. A., Campos, G. F. C., Schmiele, M., Clerici, M. T. P. S., Barbin, D. F., \& Barbon, S. (2018). Computer vision system for characterization of pasta (noodle) composition. Journal of Electronic Imaging, 27(05), 053021. https://doi.org/10.1117/1.JEI.27.5.053021

Melati, J., Lucchetta, L., Prado, N. V., Oliveira, D. F., \& Tonial, I. B. (2021). Physical and sensory characteristics of salty cereal bar with different binding agents. Food Science and Technology, 41(suppl 1), 150-154. https://doi.org/10.1590/fst.07820

Miller, K. B. (2020). Review of whole grain and dietary fiber recommendations and intake levels in different countries. Nutrition Reviews, 78(Supplement_1), 29-36. https://doi.org/10.1093/nutrit/nuz052

Miranda, A. V. S., \& Schmiele, M. (2020). Carboidratos não digeríveis como alternativa para melhorar a qualidade tecnológica e nutricional de produtos cárneos e potencial aplicação em hambúrguer de peixe. Research, Society and Development, 9(11), e87691110490. https://doi.org/10.33448/rsd-v9i11.10490

Mokrzycki, W., \& Tatol, M. (2011). Color difference Delta E - A survey. Machine Graphics and Vision, 20 (4), $383-411$.

Moreira-Araújo, R. S. R., Sousa, I. G. M., Cavalcante, R. B. M., Morgano, M. A., \& Araújo, M. A. M. (2021). Cereal bar enriched with cowpea bean whole flour, cashew nut, and raisin banana. Revista Ciência Agronômica, 52(2), 1-7. https://doi.org/10.5935/1806-6690.20210026

Nishinari, K., Fang, Y., Guo, S., \& Phillips, G. O. (2014). Soy proteins: A review on composition, aggregation and emulsification. Food Hydrocolloids, 39, 301-318. https://doi.org/10.1016/j.foodhyd.2014.01.013

Nóbile, F. O., Andrade, T. C. R., Borgea, S. F., Cantieri, J. A., \& Kawano, A. C. S. (2017). Rates of beer brewers of waste in soil fertility. Nucleus, 14(1), 335-340. https://doi.org/10.3738/1982.2278.1647 
Pallavi, B. V., Chetana, R., Ravi, R., \& Reddy, S. Y. (2015). Moisture sorption curves of fruit and nut cereal bar prepared with sugar and sugar substitutes. Journal of Food Science and Technology, 52(3), 1663-1669. https://doi.org/10.1007/s13197-013-1101-0

Pathania, S., \& Kaur, N. (2022). Utilization of fruits and vegetable by-products for isolation of dietary fibres and its potential application as functional ingredients. Bioactive Carbohydrates and Dietary Fibre, 27, 100295. https://doi.org/10.1016/j.bcdf.2021.100295

Payá, A. L., Garcia, L., Cunha, M. D. C., Crespi, N. M., Angelis, V. C., Leoni, J. N., \& Moraes, P. A. V. (2019). Produção e caracterização de cerveja artesanal adicionada de aveia (Avena sativa). Revista Engenharia em Ação UniToledo, 04(02), 52-66.

Pereira, A. S., Shitsuka, D. M., Pereira, F. J., \& Shitsuka, R. (2018). Metodologia da pesquisa científica. UFSM.

Petrovic, J., Pajin, B., Tanackov-Kocic, S., Pejin, J., Fistes, A., Bojanic, N., \& Loncarevic, I. (2017). Quality properties of cookies supplemented with fresh brewer's spent grain. Food and Feed Research, 44(1), 57-63. https://doi.org/10.5937/FFR1701057P

Prado, S. B. R., Castro-Alves, V. C., Ferreira, G. F., \& Fabi, J. P. (2019). Ingestion of non-digestible carbohydrates from plant-source foods and decreased risk of colorectal cancer: A review on the biological effects and the mechanisms of action. Frontiers in Nutrition, 6. https://doi.org/10.3389/fnut.2019.00072

Prithani, R., \& Dash, K. K. (2020). Mass transfer modelling in ultrasound assisted osmotic dehydration of kiwi fruit. Innovative Food Science \& Emerging Technologies, 64, 102407. https://doi.org/10.1016/j.ifset.2020.102407

Quiroga, A. L. B. (2013). Gelatina um agente gelificante único e natural. Revista Food ingredients Brasil, 27, 44-66.

Ramos, S. A., Pereira, R. D., Andressa, I., Schmiele, M., \& Amaral, T. N. (2020). Desenvolvimento de cookies com coprodutos de frutas. Research, Society and Development, 9(10), e5799108918. https://doi.org/10.33448/rsd-v9i10.8918

Rodrigues, M. I., \& Iemma, A. F. (2014). Experimental design and process optimization. New York: CRC Press.

Rojas, V. M., \& Gozzo, A. M. (2017). Extração e caracterização de gelatina de subprodutos suínos. Brazilian journal of Food Research, 8(2), 98-115. https://doi.org/10.3895/rebrapa.v8n2.4933

Samakradhamrongthai, R. S., Jannu, T., \& Renaldi, G. (2021). Physicochemical properties and sensory evaluation of high energy cereal bar and its consumer acceptability. Heliyon, 7(8), e07776. https://doi.org/10.1016/j.heliyon.2021.e07776

Santos, M. P., Silva, M. B., Moreira, K. G., Silveira, M. P., Silveira, J. V. W., \& Schmiele, M. (2019). Coprodutos da produção de cerveja artesanal aplicados em pães de forma integrais. In III Simpósio de Engenharia de Alimentos - Interdisciplinaridade e Inovação na Engenharia de Alimentos (p. 1164-1172). Montes Claros: UFMG.

Santos, V. S., Rodrigues, R. S., Jaekel, L. Z., Chang, Y. K., \& Schmiele, M. (2017). Dough Rheology and Technological Characteristics of Pan Bread Elaborated with the Partial Replacement of Wheat Flour via Isolated Soy Protein and Transglutaminase. In Bread: Consumption, Cultural Significance and Health Effects (p. 219-246). New York: Nova Science Publishers.

Schmiele, M. Araújo, T. L., Gurgueira, M. D., \& Chang, Y. K. (2015). Determinação da concentração de diferentes sistemas de solventes na solubilização de proteínas de análogo de carne. Ciência Rural, 45(6), 1120-1125. https://doi.org/10.1590/0103-8478cr20131630

Schmiele, M., Ferrari M. H. F., Clerici, M. T. P.S \& Chang, Y. K. (2017). Mixolab ${ }^{\mathrm{TM}}$ for rheological evaluation of wheat flour partially replaced by soy protein hydrolysate and fructooligosaccharides for bread production. LWT - Food Science and Technology, 76, 259-269. https://doi.org/10.1016/j.1wt.2016.07.014

Schmiele, M., Jaekel, L. Z., Ishida, P. M. G., Chang, Y. K., \& Steel, C. J. (2013). Massa alimentícia sem glúten com elevado teor proteico obtida por processo convencional. Ciência Rural, 43(5), 908-914. https://doi.org/10.1590/S0103-84782013000500026

Schmiele, M., Santos, M. P., Silva, M. B., \& Silveira, J. V. W. (2017). Drying kinetics of brewery brassage pomace. In 12 SLACA - Latin American Symposium of Food Science.

Schmiele, M., Silva, L. H., Costa, P. F. P., Rodrigues, R. S., \& Chang, Y. K. (2011). Influência da adição de farinha integral de aveia, flocos de aveia e isolado proteico de soja na qualidade tecnológica de bolo inglês. Boletim do Centro de Pesquisa de Processamento de Alimentos, 29(1). https://doi.org/10.5380/cep.v29i1.22751

Schmiele, M., Silveira, M. P., Leite, L. L., Felisberto, M. H. F., Clerici, M. T. P. S., \& Chang, Y. K. (2019). Macarrão instantâneo fonte de proteína e com alto teor de fibra alimentar. In III Simpósio de Engenharia de Alimentos: Interdisciplinaridade e Inovação na Engenharia de Alimentos. (p. 893-901). Montes Claros: UFMG.

Schmiele, M., Yoshida, C. Y., Gomes, P. T. G., Vidal, V. A. S., Pollonio, M. A. R., \& Chang, Y. K. (2019). Proteínas vegetais extrusadas como extensores em sistema modelo de emulsão cárnea. In III Simpósio de Engenharia de Alimentos: Interdisciplinaridade e Inovação na Engenharia de Alimentos. (p. 1124113). Montes Claros: UFMG.

Sethupathy, P., Suriyamoorthy, P., Moses, J. A., \& Chinnaswamy, A. (2020). Physical, sensory, in-vitro starch digestibility and glycaemic index of granola bars prepared using sucrose alternatives. International Journal of Food Science \& Technology, 55(1), 348-356. https://doi.org/10.1111/ijfs.14312

Shih, Y., Wang, W., Hasenbeck, A., Stone, D., \& Zhao, Y. (2020). Investigation of physicochemical, nutritional, and sensory qualities of muffins incorporated with dried brewer's spent grain flours as a source of dietary fiber and protein. Journal of Food Science, 85(11), 3943-3953. https://doi.org/10.1111/17503841.15483

Silva, B. S. (2020). Caracterização dos frutos e dos azeites de olivas produzidas em Diamantina $(M G)$ e cinética de secagem dos bagaços. Universidade Federal dos Vales do Jequitinhonha e Mucuri. Recuperado de http://acervo.ufvjm.edu.br/jspui/handle/1/2444. 
Silva, B. S., Gomes, P. T. G., Silva, I. N., \& Schmiele, M. (2019). Estruturados de frutas com adição de fibras provenientes do processo de brassagem da indústria cervejeira. In IV Jornada Regional Sudeste de Engenharia de Alimentos.

Silva, I. Q., Oliveira, B. C. F., Lopes, A. S., \& Pena, R. S. (2009). Obtenção de barra de cereais adicionada do resíduo industrial de maracujá. Alimentos e Nutrição, 20(2), 321-329.

Silva, J. D. R., Rosa, G. C. , Neves, N. A., Leoro, M. G. V., \& Schmiele, M. (2021). Production of sourdough and gluten-free bread with brown rice and carioca and cowpea beans flours: biochemical, nutritional and structural characteristics. Research, Society and Development, 10(16), e303101623992. https://doi.org/10.33448/rsd-v10i16.23992.

Simanca-Sotelo, M., Paula, C., Domínguez-Anaya, Y., Pastrana-Puche, Y., \& Álvarez-Badel, B. (2021). Physico-chemical and sensory characterization of sweet biscuits made with yacon flour (Smallanthus sonchifolius). NFS Journal, 22, 14-19. https://doi.org/10.1016/j.nfs.2020.12.001

Souza, A. R., \& Schmiele, M. (2021). Custard apple puree, fructooligosaccharide and soy protein hydrolysate as alternative ingredients in low carb pound cake. Journal of Food Science and Technology, 58(9), 3632-3644. https://doi.org/10.1007/s13197-021-05155-9

Srebernich, S. M., Gonçalves, G. M. S., Ormenese, R. C. S. C., \& Ruffi, C. R. G. (2016). Physico-chemical, sensory and nutritional characteristics of cereal bars with addition of acacia gum, inulin and sorbitol. Food Science and Technology, 36(3), 555-562. https://doi.org/10.1590/1678-457X.05416

Stelick, A., Sogari, G., Rodolfi, M., Dando, R., \& Paciulli, M. (2021). Impact of sustainability and nutritional messaging on Italian consumers' purchase intent of cereal bars made with brewery spent grains. Journal of Food Science, 86(2), 531-539. https://doi.org/10.1111/1750-3841.15601

Teotônio, D. O., Costa, B. A. F., Gomes, P. T. G., Santos, M. P., Amaral, E. F. G., Clerici, M. T. P. S., ... Schmiele, M. (2021). Fructo-oligosaccharides, hydrolyzed soy protein and yeast (Saccharomyces sp.) extract as potential cryoprotectans in gluten-free frozen dough and bread quality. Research, Society and Development, 10(3), e44510313556. https://doi.org/10.33448/rsd-v10i3.13556

Timm, T. G., Lima, G. G., Matos, M., Magalhães, W. L. E., Tavares, L. B. B., \& Helm, C. V. (2020). Nanosuspension of pinhão seed coat development for a new high-functional cereal bar. Journal of Food Processing and Preservation, 44(6), e14464. https://doi.org/10.1111/jfpp.14464

Vernaza, M. G., Dia, V. P., Mejia, E. G., \& Chang, Y. K. (2012). Antioxidant and antiinflammatory properties of germinated and hydrolysed Brazilian soybean flours. Food Chemistry, 134(4), 2217-2225. https://doi.org/10.1016/j.foodchem.2012.04.037

Vernaza, M. G., \& Chang, Y. K. (2020). Resistant starch and soy protein isolate in instant noodles obtained by conventional and vacuum frying. Brazilian Journal of Food Technology, 23, e2018239. https://doi.org/10.1590/1981-6723.23918

Xiong, M., Zheng, S., Bai, T., Chen, D., Qin, W., Zhang, Q.,Chen, H. (2022). The difference among structure, physicochemical and functional properties of dietary fiber extracted from triticale and hull-less barley. LWT - Food Science and Technology, 154, 112771. https://doi.org/10.1016/j.lwt.2021.112771

Yang, H., Li, X., Gao, J., Tong, P., Yang, A., \& Chen, H. (2017). Germination-assisted enzymatic hydrolysis can improve the quality of soybean protein. Journal of Food Science, 82(8), 1814-1819. https://doi.org/10.1111/1750-3841.13782

Yoshida, C. Y., Amorim, M. S. F., Vidal, V., Polonio, M. A. R., Chang, Y. K., \& Schmiele, M. (2017). Desempenho de extensor de carne a base de isolado proteico de soja e glúten vital em mortadela. In XXV Congresso Brasileiro de Ciência e Tecnologia de Alimentos e XX Simpósio Internacional de Alimentos da CIGR.

Zhang, C., Zhang, Y., Li, H., \& Liu, X. (2020). The potential of proteins, hydrolysates and peptides as growth factors for Lactobacillus and Bifidobacterium: current research and future perspectives. Food \& Function, 11(3), 1946-1957. https://doi.org/10.1039/C9FO02961C 